\title{
TMS-based Neuromodulation of Evoked and Induced Gamma Oscillations and Event-related Potentials in Children with Autism
}

\author{
Estate M. Sokhadze ${ }^{1,2,3^{*}}$, Manuel F. Casanova ${ }^{1,2,3}$, Ayman S. El-Baz ${ }^{3}$, Heba Elsayed Farag ${ }^{3}$, \\ Xiaoli $\mathrm{Li}^{4}$, and Yao Wang ${ }^{3,4}$ \\ ${ }^{1}$ University of South Carolina School of Medicine, Greenville, South Carolina, USA \\ ${ }^{2}$ Greenville Health System, Greenville, South Carolina, USA \\ ${ }^{3}$ University of Louisville, Louisville, Kentucky, USA \\ ${ }^{4}$ Beijing Normal University, Beijing, China
}

\begin{abstract}
Gamma oscillations are important for the integration of information and are involved in a variety of perceptual, cognitive, and motor process that are affected in autism spectrum disorder (ASD). We used gamma oscillations along with event-related potentials (ERP) as functional markers of response to repetitive transcranial magnetic stimulation (rTMS). The subjects were age- and gender-matched ASD and typically developing children (TDC). Behavioral evaluations along with evoked and induced gamma and ERPs during oddball task were collected at pre- and post-TMS in ASD group $(N=23)$ and at baseline in TDC $(N=21)$. ASD subjects were assigned to 18 sessions of rTMS over the dorsolateral prefrontal cortex. Baseline test showed significant differences between ASD and TDC groups in terms of responses to non-targets where ASD showed excessive gamma oscillations and larger ERPs as compared to the TDC group. Behavioral response differences were manifested in a lower accuracy of motor responses. The rTMS resulted in improved accuracy of response, attenuated evoked gamma responses to non-targets, and increased induced gamma to targets. Behavioral outcomes showed decreased irritability and hyperactivity scores and decreased repetitive and stereotype behaviors. There is discussed utility of gamma oscillations as biomarkers for functional diagnostics and predictions of TMS outcomes in ASD.
\end{abstract}

Keywords: autism; evoked and induced gamma oscillations; event-related potential; rTMS; behavior

Citation: Sokhadze, E. M., Casanova, M. F., El-Baz, A. S., Farag, H. E., Li, X., \& Wang, Y. (2016). TMS-based neuromodulation of evoked and induced gamma oscillations and event-related potentials in children with autism. NeuroRegulation, 3(3), 101-126. http://dx.doi.org/10.15540/nr.3.3.101

*Address correspondence to: Dr. Estate Sokhadze, Department of Biomedical Sciences, University of South Carolina School of Medicine Greenville, GHS Pediatrics, 200 Patewood Dr., Ste A200, Greenville, SC 29615, USA. Email: sokhadze@greenvillemed.sc.edu

Copyright: (c) 2016. Sokhadze et al. This is an Open Access article distributed under the terms of the Creative Commons Attribution License (CC-BY).

Edited by:

Rex L. Cannon, PhD, Neurogifted, Boynton Beach, Florida, USA

Reviewed by:

Wesley D. Center, PhD, Liberty University, Lynchburg, Virginia, USA Randall Lyle, PhD, Mount Mercy University, Cedar Rapids, lowa, USA

\section{Background}

The cerebral cortex inherent hyperexcitability demands the presence of dampening mechanisms that maintain a proper set point when acquiring and processing stimuli from other parts of the nervous system. Contrary to a tank circuit where parasitic properties decrease oscillations, the brain needs inhibition to stop runaway excitation. Inappropriate regulation of our excitatory-inhibitory (E/I) bias creates abnormal responsiveness. It is known, for example, that contusions and hemorrhages involving the cerebral cortex interfere with the action of its dampening mechanisms, thus facilitating an epileptogenic environment. Indeed, the large variety of neurological disorders manifesting seizures suggests the presence of a seesaw type of 
homeostatic mechanism in charge of managing neural activity that is precariously tilted in favor of excitation. The carefully crafted $E / I$ bias of the cerebral cortex depends on the coordinated action of both pyramidal cells and interneurons. Cell fate specification studies have shown that a variety of different interneurons develop at specific laminar locations and at different times during neurodevelopment. These cells migrate to the cortex during the entire period of corticogenesis using multiple tangential routes in order to reach their final destination (Lavdas, Grigoriou, Pachnis, \& Parnavelas, 1999). The large variety of interneurons, locations, and timing of origination helps explain the clinical heterogeneity observed when studying dysfunction of excitatory-inhibitory cell dyads.

An abnormal excitation-to-inhibition (E/l) bias provides a pathophysiological mechanism capable of explaining the complex phenotype of autism spectrum disorders (ASD). Abnormalities of E/I ratio in ASD were discussed in several reviews (Rubenstein \& Merzenich, 2003; Uzunova, Pallanti, \& Hollander, 2015). Reviewed studies provide support to theories linking autism with an altered cortical E/l balance. The oscillations in high gamma band are sensitive to the E/I balance and may appear useful in ASD studies (Stroganova et al., 2015). The power of gamma oscillations depends on a level of excitation of the inhibitory basket cells recruited by increasing strength of excitatory input. It is very logical to agree with the authors' conclusion that the experimental manipulations capable to affect gamma activity could be very useful for the investigation of proposed inhibitory neurons dysfunction in ASD (Stroganova et al., 2015). Postmortem studies in ASD indicative of heterotopias, increased cell density in the grey-white matter junction and molecular layer, minicolumnopathy, and focal cortical dysplasias indicate the presence of a neuronal migration disorder (Casanova et al., 2013; Casanova, Sokhadze, Opris, Wang, \& Li, 2015). Pathology of brain development wherein neurons are prevented from migrating to their proper location within the cerebral cortex (e.g., focal cortical dysplasias) alter the integrative action of pyramidal cell-interneuron dyads. Oscillations of pyramidal cells in minicolumns and across assemblies of minicolumns are maintained by networks of different species of inhibitory, GABA-expressing interneurons. In this regard interneurons make a critical contribution to the generation of network oscillations and help synchronize the activity of pyramidal cells during transient brain states (Mann \& Paulsen, 2007).
Local excitatory-inhibitory interactions help shape neuronal representations of sensory, motor, and cognitive variables, and produce local gamma-band oscillations in the $30-80 \mathrm{~Hz}$ range (Donner \& Siegel, 2011).

A possible relation between fast EEG activity and autism comes from data on genetically mediated abnormalities in GABAergic and glutamatergic mediator systems (Shuang et al., 2004). The morphological integrity of GABAergic interneuron connections within cortical minicolumns is important for generation of normal gamma oscillations (Whittington, Traub, Kopell, Ermentrout, \& Buhl, 2000). Casanova, Buxhoeveden, and Gomez (2003) suggested that such abnormal minicolumnar organization may result in a deficit of inhibitory GABAergic fiber projections, which in turn may facilitate the occurrence of epilepsy, sensory disorders, and gamma oscillation related abnormalities in autism. The presence of fast rhythms in EEG is usually considered as an electrophysiological index of cortical activation. Therefore, excess of beta and gamma rhythms in EEG of children with autism support the hypothesis of abnormally high excitation/inhibition ratio in cortical structures in this disorder (Casanova et al., 2003; Rubenstein \& Merzenich, 2003; reviewed in Uzunova et al., 2015).

Abnormalities of high-frequency EEG oscillations have been associated with binding problems (the coactivation of neural assemblies) present in autism and other psychiatric conditions (Brock, Brown, Boucher, \& Rippon, 2002; Grice et al., 2001). Oscillatory activity in the gamma band of the EEG has been related to cognitive functions such as attention, learning, and memory (Kaiser \& Lutzenberger, 2003). Binding of widely distributed cell assemblies by synchronization of their gamma frequency activity is thought to underlie cohesive stimulus representation in the human brain (Kahana, 2006). According to this assumption, changes in gamma EEG activity have been considered indicators of processing of Gestalt-like patterns (Herrmann \& Mecklinger, 2000, 2001; Herrmann, Munk, \& Engel, 2004; von Stein, Rappelsberger, Sarnthein, \& Petsche, 1999). Given that many of the above related functions are abnormal in ASD, gamma oscillations could therefore provide biological validation to many clinical phenomena observed in this condition.

According to some authors the "weak central coherence" (Frith \& Happé, 1994; Happé \& Frith, 2006) in autism results from a reduction in the 
integration of specialized local networks in the brain caused by a deficit in temporal binding (Brock et al., 2002). Visual and auditory perception anomalies may be attributed to a reduced coherence and synchrony of gamma activity between networks processing local features. The inability to reduce gamma activity according to Brown (2005) leads to the inability to decide which event requires attention when there are multiple choices. Excessive gamma can therefore be linked to a reduction in the ability to focus attention. The "temporal binding deficit" hypothesis of autism (Brock et al., 2002; Rippon, Brock, Brown, \& Boucher, 2007) suggests that many features of autism, such as superiority in processing detail (local processing) and disadvantages in global processing, can be explained by a failure of binding between cortical areas. Abnormalities of gamma frequency responses were reported in several studies comparing individuals with ASD with controls (Brown, 2005; Grice et al., 2001; Isler, Martien, Grieve, Stark, \& Herbert, 2010; Sokhadze, El-Baz, et al., 2009; Stroganova et al., 2012; Sun et al., 2012).

The "temporal binding" hypothesis predicts that synchronized oscillatory neural activity in gamma band range is the main mechanism (Müller, Gruber, \& Keil, 2000) by which various brain regions form one percept and feature binding (Gray, König, Engel, \& Singer, 1989). In human EEG studies with recordings from the scalp, according to Ford, Gray, Faustman, Heinks, and Mathalon (2005) there is an accumulating evidence that gamma-range oscillations and synchrony of the oscillations between neurons and neuronal networks represent a basic mechanism of information coding and integration (Fernández, Fell, \& Fries, 2002; Fries, 2009; Keil, Müller, Ray, Gruber, \& Elbert, 1999; Lenz, Schadow, Thaerig, Busch, \& Herrmann, 2007; Müller et al., 1996; Müller \& Gruber, 2001; Singer, 1999; Werkle-Bergner, Shing, Müller, Li, \& Lindenberger, 2009).

Electroencephalography (EEG) has been used to decompose oscillatory patterns into several frequency bands: delta $(0.5-4.0 \mathrm{~Hz})$, theta $(4-8 \mathrm{~Hz})$, alpha $(8-13 \mathrm{~Hz})$, beta $(13-30 \mathrm{~Hz})$, and gamma $(30-$ $80 \mathrm{~Hz}$ ), each of which operates over various spatiotemporal scales to control cortical activity. High-frequency EEG oscillations in the gamma range, especially those centered around $40 \mathrm{~Hz}$, are intimately related to mental processes such as consciousness (Joliot, Ribary \& Llinás, 1994; Llinás \& Ribary, 1993), binding of sensory features into coherent percept (Engel \& Singer, 2001; TallonBaudry, Bertrand, Delpuech, \& Pernier, 1996; Tallon-Baudry, Bertrand, Hénaff, Isnard, \& Fischer,
2005), object representation (Bertrand \& TallonBaudry, 2000), attention (Fell et al., 2001; Sheer, 1976), and memory (Herrmann et al., 2004). Gamma oscillations are subdivided into spontaneous and stimulus related (steady-state, induced and evoked oscillations), but these different classes of gamma oscillations may be generated in the same neural circuits (Herrmann \& Knight, 2001). High-frequency rhythms such as gamma are generated in neuronal networks involving excitatory pyramidal cells and inhibitory gamma-aminobutyric acid GABAergic interneurons (Whittington et al., 2000).

Gamma-band activity in response to stimulation can be divided into either evoked or induced: evoked gamma-band activity has been identified at a latency of around 100 milliseconds after stimulus onset (Bertrand \& Tallon-Baudry, 2000; Herrmann \& Mecklinger, 2001) and is highly phase locked to the onset of the stimulus; induced gamma-band activity occurs later with a variable onset although it has been reported to start at around 250 milliseconds (Brown, Gruber, Boucher, Rippon, \& Brock, 2005). It has been proposed that evoked gamma-band activity reflects the early sensory processing and the binding of perceptual information within the same cortical area (i.e., intra-areal), whereas induced gamma-band activity reflects the binding of feedforward and feed-back processing in a whole network of cortical areas (Brown et al., 2005; Müller et al., 2000; Shibata et al., 1999). Variations of such activity have been termed event-related synchronization and desynchronization (ERS/ERD) (Pfurtscheller \& Aranibar, 1977) or event-related spectral perturbations (ERSP; Makeig et al., 2002) and have been associated with the activation of task-relevant neuronal assemblies (Pfurtscheller \& Lopes da Silva, 1999; Rippon et al., 2007).

Karakaş, Başar-Eroğlu, Özesmi, Kafadar, and Erzengin (2001) argued that early (evoked) gamma response represents sensory processing; and basically represents a phenomenon of the sensory register. In their study it was shown that the evoked gamma responses at frontocentral recording sites at the early time window of $0-150 \mathrm{~ms}$ occurred irrespective of experimental paradigm and did not vary as a function of task complexity or attention allocation. According to the authors, the gamma responses obtained as a non-phase-locked response in the later time window (approximately 150-400 milliseconds), primarily under task conditions that require pattern recognition or higher order recognition processes of the short-term memory, represent perceptual-cognitive processes. 
In a later refinement of the interpretation of oscillatory gamma frequency responses during experimental manipulations, Herrmann et al. (2004) suggested that early (evoked) gamma responses reflect sensory-memory matching processes, whereas late (induced) gamma response might be indexing response selection or context updating. The same information processing stages are reflected as well in exogenous (e.g., N100) and endogenous (e.g., N200, P300) event-related potentials (ERP). Therefore, there should be an association between key features of evoked and induced EEG responses in gamma range, ERPs, and perception and cognitive processes that are known to be deficient in autism.

There are only a few EEG studies employing restingstate examinations in individuals with ASD, and practically all of them report oscillatory anomalies. Specifically, eyes-open resting-state exams have shown greater relative delta and less relative alpha power in 4- to 12-year-old low-functioning children with ASD (Cantor, Thatcher, Hrybyk, \& Kaye, 1986), and greater $24-44 \mathrm{~Hz}$ power in 3- to 8-year-old boys with ASD (Orekhova et al., 2007). Eyes-closed exams have shown greater relative 3-6 $\mathrm{Hz}$ and $13-$ $17 \mathrm{~Hz}$ power and less $9-10 \mathrm{~Hz}$ power in adults with ASD (Murias, Webb, Greenson, \& Dawson, 2007), and decreased delta and beta power, as well as increased theta power, in children with ASD (Coben, Chabot, \& Hirschberg, 2013; Coben, Clarke, Hudspeth \& Barry, 2008). Although the aforementioned results implicate an atypical oscillatory activity in ASD, findings are discrepant and probably due to between-study differences in age, level of functioning, and medication status of the ASD participants. Cornew, Roberts, Blaskey, and Edgar (2012) showed that children with ASD exhibited regionally specific elevations in delta, theta, alpha, and high-frequency beta and gamma power, supporting an imbalance of neural excitation/inhibition as a neurobiological feature of ASD. Of particular interest was the authors' report that increased temporal and parietal alpha power was associated with greater symptom severity. In the auditory domain, reduced entrainment to auditory stimulation at $40 \mathrm{~Hz}$ in participants with ASD (Wilson, Rojas, Reite, Teale, \& Rogers, 2007) has been demonstrated. In contrast, during visual perception there is evidence for both hyperactivity and hypoactivity of gamma-band oscillations (Brown et al., 2005; Grice et al., 2001; Isler et al., 2010; Milne, Scope, Pascalis, Buckley, \& Makeig, 2009; Rojas \& Wilson, 2014; Stroganova et al., 2007, 2012, 2015; Uhlhaas \& Singer, 2007), raising the question of the link between high-frequency oscillations and perceptual dysfunctions in the disorder. Orekhova et al. (2007) reported higher levels of EEG gamma-band activity in children with ASD. Elevations in gamma were observed in anterior temporal, posterior temporal, and occipital sites using EEG (Cornew et al., 2012). Therefore, gamma-band abnormalities have been reported in many studies of autism spectrum disorders. Gamma-band activity is associated with perceptual and cognitive functions that are compromised in autism. Despite all of the evidence, the utility of gamma-band related variables as diagnostic biomarkers is currently unexplored, suggesting an urgent need for using gamma oscillation measures as functional markers of response to interventions such as transcranial magnetic stimulation (TMS)based neuromodulation or neurofeedback.

Repetitive transcranial magnetic stimulation (rTMS) is one of the most promising neuromodulation techniques for the treatment of ASD symptoms, as it offers a noninvasive method for altering excitability of the cortex. TMS induces a short-term functional reorganization in the human brain. The magnitude and the direction of neuroplasticity evoked by rTMS depend on the parameters of magnetic stimulation (intensity, frequency, number of stimuli per session, number of sessions, etc.) and the functional state of the cortical topography targeted by rTMS. Since effects of rTMS are not limited to the stimulated target cortex but give rise to functional changes in anatomically and functionally interconnected cortical areas, rTMS is a suitable tool to investigate mechanisms of neural plasticity within a distributed functional network (Rossi \& Rossini, 2004; Ziemann, 2004). The lasting effects of rTMS offer new possibilities to study dynamic aspects of the pathophysiology of a variety of diseases and may have therapeutic potential in some psychiatric disorders. By convention, rTMS in $0.3-1.0 \mathrm{~Hz}$ frequency range is referred to as "slow," whereas "fast" rTMS refers to stimulation greater than $1 \mathrm{~Hz}$ (Pasquale-Leone, Walsh, \& Rothwell, 2000). This point of view is reconsidered as a certain simplification, as some studies consider the frequency of TMS as a less important factor compared to other factors related to ability to change functional connectivity in the brain (Fitzgerald et al., 2011; Khedr, Rothwell, Ahmed, \& El-Atar, 2008). Hoffman and Cavus (2002) in their review of slow rTMS studies proposed long-term depression and long-term depotentiation as models for understanding the mechanism of slow rTMS. Neocortical long-term depression and changes in the cortical excitability induced by slow rTMS appear to accumulate in an additive fashion as the number 
of stimulations is increased over many days. Studies of both slow rTMS and long-term depression suggest additive efficacy when higher numbers of stimulations are administered. The reversal, or depotentiation, of previously enhanced synaptic transmission due to long-term potentiation may be the most relevant model for slow rTMS when used as a therapeutic tool. More detailed account of biophysical effects of TMS can be found in the review by Wagner, Rushmore, Eden, and ValeroCabre (2009).

TMS is generally regarded as safe without lasting side effects. Reported side effects include a mild, transient tension-type headache on the day of stimulation and mild discomfort due to the sound of the pulses. There is a certain risk of inducing a seizure (Wasserman et al., 1996); participants with epilepsy or a family history of epilepsy are generally excluded from rTMS studies and, as a safety precaution, some rTMS studies adjust the stimulation intensity below the participant's motor threshold (e.g., $80 \%$ or $90 \%$ ). Though rTMS is generally considered safe for use in pediatric populations, as no significant adverse effects or seizures have been reported (Garvey \& Gilbert, 2004; Quintana, 2005), the question still remains open whether rTMS is sufficiently safe for application in children. Quintana (2005) evaluated studies that used TMS in persons younger than 18. The 48 studies reviewed involved a total of 1,034 children; 35 of the studies used single-pulse TMS (980 children), 3 studies used paired TMS (20 children), and 7 studies used rTMS ( 34 children). The TMS studies in persons younger than 18 has been used to examine the maturation and activity of the neurons of various central nervous system tracts, plasticity of neurons in epilepsy, multiple sclerosis, myoclonus, transcallosal inhibition, and motor cortex functioning with no reported seizure risk (Garvey \& Gilbert, 2004; Lin \& Pascual-Leone, 2002). Repetitive TMS has been applied in children with psychiatric disorders such as ADHD, ADHD with Tourette's, and depression. Although there are limited number of studies using rTMS in children, these studies did not report significant adverse effects or seizures. Review of state-of-art rTMS application in ASD treatment and research can be found in several current reviews (Casanova \& Sokhadze, 2014; Casanova et al., 2015; Oberman, Rotenberg, Pascual-Leone, 2013; Sokhadze, Casanova, \& Baruth, 2013), and they all call for the need for more research clinical trials aimed to prove efficacy of the method. rTMS has been applied to a wide variety of psychiatric (e.g., ADHD, depression) and neurological disorders (e.g., Parkinson's disease) in adult populations, and more recently rTMS has been applied in child and adolescent populations (see Croarkin, Wall, \& Lee, 2011). A number of studies report an improvement in mood after repeated frontal lobe stimulation in both depressed adults (George et al., 2010) and adolescents (Wall et al., 2011). Furthermore, it has been found that rTMS may improve certain symptoms associated with anxiety disorders, like Posttraumatic Stress Disorder (PTSD) and Obsessive-compulsive Disorder (OCD; George \& Belmaker, 2007). In Parkinson's disease (PD) most studies have shown beneficial effects of rTMS on clinical symptoms (Wu, Fregni, Simon, Deblieck, \& Pascual-Leone, 2008). Currently only rTMS-based therapy of treatment-resistant major depression has FDA approval; however, it is very likely that in the future rTMS will be approved for the treatment of other mental and neurological disorders as well.

Recent reviews (Casanova et al., 2015; Oberman et al., 2013; Sokhadze, Casanova, et al., 2013) provide detailed account of current status of rTMS application in autism research and treatment. Within the context of autism spectrum disorder, rTMS has unique applications as a treatment modality. A wide range of deficits in autism might be understood by an increase in the ratio of cortical excitation to cortical inhibition (Rubenstein \& Merzenich, 2003) and increases in local cortical connectivity accompanied by deficiencies in long-range connectivity (Just, Cherkassky, Keller, \& Minshew, 2004; Minshew \& Williams, 2007; Rippon et al., 2007). An increased ratio of cortical excitation to inhibition and higher than normal cortical 'noise' may explain the strong aversive reactions to auditory, tactile, and visual modality stimuli frequently reported in autism (Gillberg \& Billstedt, 2000). Ogawa et al. (2004) examined the changes in highfrequency oscillations (HFOs) of somatosensory evoked potentials (SEPs) before and after slow rTMS over the right primary somatosensory cortex $(0.5 \mathrm{~Hz}, 50$ pulses, $80 \%$ motor threshold intensity). The HFOs, which represent a localized activity of intracortical inhibitory interneurons, were significantly increased after slow rTMS, while the SEPs were not changed. Their results suggest that slow rTMS affects cortical excitability by modulating the activity of the intracortical inhibitory interneurons beyond the time of the stimulation and that rTMS may have therapeutic effects on such disorders. This is in line of our hypothesis in which slow rTMS will increase activity of inhibitory cells in minicolumn which will then enhance spatial contrast needed to enhance functional discrimination. 
Our group's prior studies were aimed to examine effects of low-frequency $(0.5-1.0 \mathrm{~Hz})$ rTMS on behavioral, quantitative EEG, and event-related potential (ERP) outcomes in children and adolescents with autism. In a series of studies, we used rTMS over the dorsolateral prefrontal cortex (DLPFC) on a weekly basis for 6,12 , and 18 weeks in individuals with autism randomly assigned to active treatment group and wait-list groups. We predicted that post-TMS changes in the active treatment group, as compared to the wait-list group, can be detected during repeated tests using the same functional outcome measures (EEG, ERP, etc.) in cognitive task. Our prediction was that slow rTMS of DLPFC will result in an alteration of cortical inhibition through the activation of inhibitory GABAergic interneurons leading to an improvement in the cortical excitatory/inhibitory balance. In our methodological approach, we hypothesized that contrary to other inhibitory cells (i.e., basket and chandelier), whose projections keep no constant relation to the surface of the cortex, the geometrically exact orientation of double-bouquet cells and their location at the periphery of the minicolumn (inhibitory surround) makes them the appropriate candidate for induction by a magnetic field applied parallel to cortex. Over a course of treatment 'slow' rTMS may restore the balance between cortical excitation and cortical inhibition and may lead to improved long-range cortical connectivity. Thus far we have focused on clinical, behavioral, and electrocortical outcome measures (i.e., ERPs, evoked and induced gamma oscillations), in order to access the effectiveness of rTMS treatment in ASD.

In the first of our previous investigations (Sokhadze, El-Baz, et al., 2009) we measured the EEG gamma band in eight children with ASD and five wait-list participants with ASD during a visual attention task, and then measured the EEG gamma band in the active treatment group after six sessions of 'slow' rTMS to the prefrontal cortex. Study used also 13 age-matched, typically developing children as a control group. We hypothesized that the ASD group would have excess gamma-band activity due a lack of cortical inhibition and treatment with 'slow' rTMS would help restore inhibitory tone (i.e., reduce excess gamma-band activity). We also analyzed clinical and behavioral questionnaires assessing changes in symptoms associated with ASD after rTMS treatment. The visual attention task employed Kanizsa illusory figures (Kanizsa, 1976) which have been shown to readily produce gamma oscillations during visual tasks. Subjects were instructed to press a button when they saw the target Kanizsa square and ignore all other stimuli: Kanizsa stimuli consist of inducer disks of a shape feature and either constitute an illusory figure (square, triangle) or not (colinearity feature); in nonimpaired individuals gamma activity has been found to increase during the presentation of target visual stimuli compared to non-target stimuli. We found that the power of gamma oscillations was higher in the ASD group and had an earlier onset compared to controls, especially in response to non-target illusory figures over the prefrontal cortex. Additionally, there was less of a difference in gamma power between target and non-target stimuli in the ASD group particularly over lateral frontal and parietal recording sites. After six sessions of 'slow' rTMS applied to the left prefrontal cortex, the power of gamma oscillations to non-target Kanizsa figures dramatically decreased at the frontal and parietal sites on the same side of stimulation, and there was more of a difference between gamma responses to target and non-target stimuli. According to clinical and behavioral evaluations, the ASD group showed a significant improvement on the repetitive behavior scale (RBS), which assesses repetitive and restricted behavior patterns associated with ASD (e.g., stereotyped, self-injurious, compulsive, and restricted range behaviors; Bodfish, Symons, \& Lewis, 1999; Bodfish, Symons, Parker, \& Lewis, 2000).

In a second study with another pool of participants (Baruth, Casanova, El-Baz, et al., 2010; Casanova et al., 2012; Sokhadze et al., 2012) we investigated gamma-band activity in 16 subjects with ASD in rTMS group and nine age-matched controls using Kanizsa illusory figures and assessed the effects of 12 sessions of bilateral 'slow' rTMS applied to the prefrontal cortices in TMS group of the ASD participants. In individuals with ASD, gamma activity was not discriminative of stimulus type; whereas in controls, early gamma power differences between target and non-target stimuli were highly significant. Following rTMS individuals with ASD showed significant improvement in discriminatory gamma activity between relevant and irrelevant visual stimuli, and there was also a significant reduction in irritability and repetitive behavior as a result of rTMS.

In one more pilot study on 16 children with ASD in 18-sessions-long 1- $\mathrm{Hz}$ rTMS course we also reported (Hensley, El-Baz, Sokhadze, Sears, \& Casanova, 2014) that post-TMS gamma coherence to the target condition between the frontal (F3) and temporal (T7) sites improved in both the evoked $(100-200 \mathrm{~ms})$ and in the induced (300-600 ms) gamma range responses. In addition to 
improvement in coherence between pre- and postTMS, differences were also observed in the subjects' responses to target and non-target stimuli following TMS neurotherapy. Analysis of evoked gamma coherence between F4 and T8 to both target and non-target stimuli indicate that before treatment, non-target coherence was 0.43 and target coherence was 0.45 , fairly similar values. However, after completion of TMS therapy target coherence increased to 0.56 , and non-target coherence decreased to 0.42 . The $p$-value of the comparison of coherence for F4-T8 between target and nontarget for both pre- and posttreatment was reaching significance level $(p=0.044)$. Another significant effect of TMS treatment was observed in evoked gamma coherence between F4 and P4. As in the case above, coherence in response to the target condition increased significantly following TMS. Coherence in response to the non-target stimuli increased only slightly after the TMS course, and it was not statistically significant. The comparison of mean coherence values for F4-P4 between target and non-target stimuli pre- and post-TMS treatment reached significance. Children with ASD in the waitlist group $(N=16)$ also completed two Kanizsa tasks but did not receive TMS treatment between the first and second Kanizsa task. Analysis of evoked gamma coherence between F4 and T8 for those in the wait-list group does not show significant differences in responses to target and non-target stimuli. Similarly, no significant differences were observed in responses to target and non-target stimuli for evoked gamma coherence between F4 and P4. The changes in evoked and induced gamma power to targets, accompanied by increased phase coherence between frontal and parietal sites, along with increased centroparietal and parietooccipital P100 and P300 (P3b) to targets, are indicative of more efficient processing of information post-TMS treatment. The findings point at the rationale for using ERP analysis in gamma oscillation studies. According to the classical view, ERPs reflect phasic bursts of activity in one or more discrete brain regions that occur time-locked to particular events of interest, whereas the background EEG comprises activity that is uncorrelated with these events and a mixture of ongoing rhythmic activity that reflects the overall state of the processing network (e.g., Gevins, Smith, McEvoy, \& Yu, 1997; Pfurtscheller \& Lopes da Silva, 1999) and ERPs evoked by nonexperimental events. At various times over the last 40 years, however, the classical view has been challenged by the proposal that ERPs should not be regarded as uncorrelated with the background EEG, but are instead generated by event-related reorganization of this ongoing rhythmic activity (Başar, 1980; Başar, Schürmann, Başar-Eroglu, \& Demiralp, 2001; Karakaş \& Başar, 1998; Karakaş, Erzengin, \& Başar, 2000; Karakaş et al., 2006; Luu et al., 2001; Makeig et al., 2002). Experimental evidence suggests that sensory perceptual processes are accomplished by a dynamic matching of anticipatory self-generated activity with activity generated by incoming stimulation, therefore combining top-down and bottom-up influences (Engel \& Singer, 2001). In all cases, it is important to analyze ERP along with evoked and induced gamma activity, as ERP components provide very accurate timing of information processing and inform about stages of gamma oscillation bursts even though they may have different origin and frequency range.

Information about stages of information processing can be obtained from ERP, even though the main object of our study was analysis of evoked and induced gamma responses rather than ERP responses. In general, ERPs can be categorized as short-latency (exogenous, e.g., N100) or longlatency (endogenous, e.g., P300) ERPs, which reflect early-stage, modality-specific and late-stage polymodal associative processing, respectively. It has been assumed that early components (e.g., P100, N100) reflect exogenous processes modulated by the physical attributes of the stimulus (i.e., brightness for visual stimuli), but not by cognitive processes (Coles \& Rugg, 1995). However, many studies have shown that attention processes may operate at the early stage (e.g., before 200 milliseconds) and can influence stimulus processing at the later stage (Herrmann \& Knight, 2001). P100 may reflect a facilitation of early sensory processing of attended stimuli, while N100 may reflect the orienting of attention towards taskrelevant target stimuli (Hillyard \& Anllo-Vento, 1998; Luck, Heinze, Mangun, \& Hillyard, 1990; Näätänen \& Michie, 1979). Posterior visual P100 are generated within the fusiform gyrus (Heinze et al., 1994), whereas N100 is probably generated by distributed dipoles in the lateral extrastriate cortex (Gomez-Gonzales, Clark, Fan, Luck, \& Hillyard, 1994) with contribution from parieto-occipital and occipitotemporal areas (Yamazaki et al., 2000). Anterior P100 and N100 components occurring within a comparable time window result from frontal generators (Clark, Fan, \& Hillyard, 1995).

The most studied endogenous ERP is the P300 (300-500 ms poststimulus). The P300 obtained in an oddball paradigm with three stimuli in a random order, one of them frequent (standard), another one rare (target), and one more infrequent (non-target, 
novel distractor). It was reported that these novels elicit a frontocentral P300, so-called P3a, whereas the rare targets elicit a parietally distributed $\mathrm{P} 300$, so-called P3b (Katayama \& Polich, 1998; Polich, 2003; Pritchard, 1981). The P3a is recorded at the anterior locations and reflects frontal lobe activity (Friedman, Simpson, \& Hamberger, 1993; Knight, 1984). In a three-stimuli oddball task the P3a is interpreted as "orienting" and the P3b as an index of ability to sustain attention to target. Source localization techniques have claimed that multiple brain areas are involved in the generation of the visual P3b: the hippocampus and parahippocampal areas, the insula, the temporal lobe, occipital cortex, and the thalamus (Goto, Brigell, \& Parmeggiani, 1996; Herrmann \& Knight, 2001; Mecklinger et al., 1998; Rogers, Basile, Papanicolaou, \& Eisenberg, 1993). Most studies agree that the P3b has multiple dipole sources (Halgren, Marinkovic, \& Chauvel, 1998; Knight, 1997; Townsend et al., 2001).

Traditionally there was less attention devoted to such negative endogenous ERP component as N200 (N2b), detectable over centroparietal scalp locations and occurring about 180 and 320 milliseconds poststimulus (Näätänen, Gaillard, \& Mäntysalo, 1978; Näätänen, Schröger, Karakaş, Tervaniemi, \& Paavilainen, 1993). This component is associated with categorization, perceptual closure and attention focusing ultimately signaling that a perceptual representation has been formed (Potts, Patel, \& Azzam, 2004). The posterior visual N2b is enhanced if the presented stimulus contains a perceptual feature or attribute defining the target in the task. A frontal positive component (P2a) in a latency range comparable with the posterior $\mathrm{N} 2 \mathrm{~b}$ (i.e., $180-320 \mathrm{~ms}$ poststimulus) has been reported in working memory and attention tasks. The P2a recorded over inferior prefrontal recording sites appears to be selectively responsive to the evaluation of the task relevance of presented visual stimuli, and source localization places dipoles of this component in the orbitofrontal cortex (Potts, Dien, Hartry-Speiser, McDougal, \& Tucker, 1998; Potts, Liotti, Tucker, \& Posner, 1996). Kenemans, Kok, and Smulders (1993) described this frontal positivity as a component that indexes the hierarchical selection of task-relevant features for further processing.

The goal of the current study was (1) to compare behavioral (reaction time, accuracy) and electrocortical biomarkers (frontal and parietal ERP, evoked and induced gamma amplitude) of executive functions during performance on a visual threestimuli oddball task with illusory figures between children with autism spectrum disorder and typically developing children, (2) to analyze group differences, and (3) to explore if 18 weekly sessions of low-frequency rTMS administered bilaterally over DLPFC in children with ASD will improve behavioral, ERP and evoked and induced gamma measures during posttreatment test in the same oddball tasks. In addition, we analyzed clinical behavioral questionnaires post-TMS outcomes (ABC [Aman \& Singh, 1994] and RBS [Bodfish et al., 1999]).

\section{Methods}

Participants with ASD (age range 8 to 19 years) were recruited through the University of Louisville Weisskopf Child Evaluation Center (WCEC). Diagnosis was made according to the Diagnostic and Statistical Manual of Mental Disorders (DSM-IVTR; APA, 2000) and further ascertained with the Autism Diagnostic Interview-Revised (ADI-R; Le Couter, Lord, \& Rutter, 2003). They also had a medical evaluation by a developmental pediatrician. All subjects had normal hearing based on past hearing screens. Participants with a history of seizure disorder, significant hearing or visual impairment, a brain abnormality conclusive from imaging studies, or an identified genetic disorder were excluded. Twenty participants were highfunctioning children with autism (HFA) diagnosis and five had Asperger Syndrome. All had full-scale IQ > 80 assessed using the Wechsler Intelligence Scale for Children, Fourth Edition (WISC-IV; Wechsler, 2003) or (for adolescents) the Wechsler Abbreviated Scale of Intelligence (WASI; Wechsler, 1999). Two subjects (one HFA and one Asperger boy) were excluded from the analysis as they did not comply with EEG/ERP test instructions, thus leaving only 23 children with ASD in the study (mean age $13.6 \pm$ 3.22 [standard deviation, $S D$ ] years, 17 boys, 6 girls). The group of typically developing (TD) children comprised of 21 subjects ( 14 boys, 7 girls) with mean age $14.9 \pm 4.3$ years. Enrolled autistic patients $(N=23)$ were assigned to $1.0 \mathrm{~Hz}$ TMS treatment (TMS group) with pre- and post-TMS course oddball tests and clinical behavioral evaluations, while 21 TD children were assigned only to one-time oddball test and served as a contrast group. There was not a significant difference in either age, gender, or socioeconomic status of parents between the TMS and TD groups.

The study complied with all relevant national regulations and institutional policies and has been approved by the local Institutional Review Board (IRB). Participating subjects and their parents (or legal guardians) were provided with full information 
about the study including the purpose, requirements, responsibilities, reimbursement, risks, benefits, alternatives, and role of the local IRB. The subjects were reimbursed only for participation in oddball EEG tests (\$25 per test). The consent and assent forms approved by the IRB were reviewed and explained to all subjects who expressed interest to participate. All questions were answered before consent signature was requested. If the individual agreed to participate, both she/he and parent/guardian signed and dated the consent or assent form and received a copy countersigned by the investigator who obtained consent.

Three-stimuli oddlball task with Kanizsa figures The stimuli employed in the test were Kanizsa square (target), Kanizsa triangle (non-target), nonKanizsa square, and non-Kanizsa triangle (standards; Kanizsa, 1976). The task represents a classic three-stimuli oddball with infrequent illusory Kanizsa target (square, 25\%) and infrequent Kanizsa distractor (triangle, 25\% ) figures presented for 250 ms among frequent non-Kanizsa stimuli (socalled standards, $50 \%$ ) with intertrial interval (ITI) varying in $1,100-1,300 \mathrm{~ms}$ range. In total 240 trials were presented following a brief practice block. The practice block had 20 trials only with the experimenter present in the room to make sure that subject correctly understood test conditions and recognized target stimuli. The total time of the test including sensors application and practice trial was under 30 minutes. For better habituation and adaptation to experimental setting, the participants with ASD diagnosis were encouraged to have at least one session for conditioning to EEG sensor net (without performing task) and getting familiar with laboratory environment.

\section{Event-related potential (ERP) acquisition and processing}

Electroencephalographic (EEG) signals from 128 sites were recorded with a dense-array EGI system (Electrical Geodesics, Inc., Eugene, OR). Subjects were placed in an electrically and acoustically isolated camera from the Industrial Acoustics Co. (Bronx, NY). Stimulus presentation and motor response collection was controlled using E-Prime v1.0 (Psychology Software Tools, Inc., Sharpsburg, PA). Visual stimuli were presented on a flat monitor located $45-50 \mathrm{~cm}$ from the subject, and motor responses were registered with a keypad (Serial Response Box; Pychology Software Tools, Inc., Sharpsburg, PA). Sampling rate of EEG was 500 $\mathrm{Hz}$, and analog Notch (60 Hz, IIR) and analog elliptical bandpass filters were set at $0.1-200.0 \mathrm{~Hz}$.
Impedances were kept under $40 \quad \mathrm{~K} \Omega$ as recommended by the EGI manuals.

ERP. Stimulus-locked EEG data was segmented offline into $200 \mathrm{~ms}$ prestimulus baseline to $800 \mathrm{~ms}$ epoch poststimulus. EEG recordings were screened for artifacts and trials with eye blinks; gross movements were removed using EGI software artifact rejection tools (Fletcher, Kussmaul, \& Mangun, 1996; Luu et al., 2001; Srinivasan, Tucker, \& Murias, 1998). The remaining artifact-free EEG recordings for trials with correct responses were digitally filtered using Notch filter (IIR, fifth-order) and 0.3-20.0 Hz IIR elliptical bandpass filter. Averaged ERP data was baseline corrected $(200 \mathrm{~ms})$, and ERPs after averaging and baseline correction were re-referenced into an average reference frame. Response-locked EEGs were segmented into 500 $\mathrm{ms}$ preresponse to $500 \mathrm{~ms}$ postresponse (i.e., commission error). More detailed account for experimental procedure and EEG data acquisition and processing can be found in our prior publications that used similar methodology (Baruth et al., 2011; Baruth, Casanova, El-Baz, et al., 2010; Baruth, Casanova, Sears, \& Sokhadze, 2010; Casanova et al., 2012; Casanova \& Sokhadze, 2014; Sokhadze et al., 2012; Sokhadze, El-Baz, et al., 2009; Sokhadze, El-Baz, Sears, Opris, \& Casanova, 2014; Sokhadze, El-Baz, Tasman, et al., 2014).

Stimulus-locked dependent ERP variables. Dependent variables for the frontal and frontocentral region of interest (ROI) were amplitude of $\mathrm{N} 100(80-$ $180 \mathrm{~ms}$ ), N200 (220-350 ms), and P3a (300-600 $\mathrm{ms}$ ), and for the parietal and parieto-occipital ROI were P100 (120-180 ms), N200 (180-320 ms), and P3b (320-600 ms) ERP waves.

Response-locked dependent variables (ERN/Pe). Response-locked dependent variables in this study were amplitude and latency of the error-related negativity (ERN, peaking within 40-150 ms posterror) and error-related positivity (Pe, peaking within 100-300 ms post-error). The ROI for both ERN and $\mathrm{Pe}$ components included $\mathrm{FCz}$, sites between $\mathrm{FCz}$ and $\mathrm{FC} 3-\mathrm{C} 1$, and between $\mathrm{FCz}$ and FC2-C2.

Evoked and induced gamma oscillations. Analysis of gamma oscillations was performed on a trial-bytrial basis. Data set was not re-referenced for average reference frame but rather was left with initial $\mathrm{Cz}$ reference to avoid gamma wave distortions. The filtering technique of individual trials of recorded EEG had several steps. EEG data collected from the task was first processed via wavelet analysis. 
This technique allows for visualization of the collected signals in both the time and frequency domains, providing information about the amplitude of gamma waveforms at varying frequencies within the selected time interval. A one-dimensional continuous wavelet transform was performed using the MATLAB Wavelet Toolbox. The Morlet window was selected as the mother wavelet in this analysis. For each signal 128 wavelet coefficients were found. Following wavelet analysis, a custom Harris bandpass filter was applied to the signals to isolate frequencies of interest. This filter allowed for the passage of the gamma frequencies between 35 and $45 \mathrm{~Hz}$ with a $2-\mathrm{Hz}$ attenuation band. A similar Wavelet Harris filtering technique was used in previous gamma analysis study on neurofeedback effects on cue reactivity in patients with substance abuse (Horrell et al., 2010) and in a study of induced gamma responses to facial expressions in autism and ADHD (Gross et al., 2012).

We selected the following EEG channels for the analysis: F1, F2, F7, F8 from the frontal area, and P3, P4, P7, P8 from the parietal area; this channel configuration allowed us to analyze gamma-band activity over both hemispheres. Reference site was midline $\mathrm{Cz}$, and analysis was conducted on trial-bytrial basis. All recorded signals entered in gamma analysis were first automatically and then manually inspected for artifacts and rejected if eye movement artifacts, gross movements, or EEG sensor drifts were detected. For automatic detection, we computed the standard in a moving time window and the normalized cross correlation coefficient between the current recoded signal and previous succeeded trials; the current recorded signal was rejected if thresholds exceeded two standard deviations or exceeded normalized cross correlation. The standard deviation threshold was in the $35-50 \mu \mathrm{V}$ range, and normalized cross correlation was approximately 0.5 . At least 30 trials of the nontarget or target Kanizsa trials were considered a sufficient number for reliable evoked and induced gamma amplitude calculations in each condition.

\section{Transcranial magnetic stimulation}

Repetitive TMS was administered using a Magstim Rapid device (Magstim Company Ltd., Whitland, UK) with a 70-mm figure-eight coil. Threshold of motor response (MT) was identified for each hemisphere in all participants with autism by increasing the output of the stimulator by $5 \%$ until a $50 \mu \mathrm{V}$ deflection or a visible twitch in the First Dorsal Interosseous (FDI) muscle was detected in at least three trials of stimulation over the motor cortex controlling the contralateral FDI. Electromyographic (EMG) responses were recorded with a C2 multichannel physiological monitoring device with USE3 Physiolab software (J\&J Engineering, Inc., Poulsbo, WA).

The TMS was administered weekly for 18 weeks; the first six treatments were over the left DLPFC, the next six were over the right DLPFC, and the remaining six treatments were done bilaterally over the DLFC (evenly at the left and right DLPFC). The DLPFC site for magnetic stimulation was found by placing the TMS coil $5 \mathrm{~cm}$ anterior, and in a parasagittal plane, to the site of maximal FDI response. A swimming cap was used to make the TMS coil positioning easier. TMS was administered at $1.0 \mathrm{~Hz}$ frequency and $90 \% \mathrm{MT}$. There were a total of 180 pulses per day session with nine trains of 20 pulses each. There were $20-30$ s between the trains intervals used. The decision to select $90 \%$ of the MT was based on prior publications where rTMS was used for the stimulation of DLPFC in various neuro and psychiatric disorders (reviewed in Daskalakis, Christensen, Fitzgerald, \& Chen, 2002; Gershon, Dannon, \& Grunhaus, 2003; Loo \& Mitchell, 2005; Oberman et al., 2013; Pascual-Leone et al., 2000; Wassermann et al., 1996; Wassermann \& Lisanby, 2001; Wassermann \& Zimmermann, 2012).

\section{Clinical social and behavioral evaluation outcomes}

For the evaluation of social and behavioral functioning we utilized caregiver reports and clinician ratings of improvement. Every participant was evaluated before TMS course and within 2 weeks following TMS treatment. Aberrant Behavior Checklist (ABC; Aman, 2004; Aman \& Singh, 1994) is a clinician-administered rating scale to assess Irritability, Lethargy/Social Withdrawal, Stereotypy, Hyperactivity, and Inappropriate Speech based on parent or caregiver report. Repetitive Behavior Scale-Revised (RBS-R; Bodfish et al., 1999) is a caregiver-completed rating scale assessing stereotyped, self-injurious, compulsive, ritualistic, sameness, and restricted range (Bodfish et al., 2000).

\section{Statistical analysis}

The primary model for statistical analyses of subjectaveraged ERP, evoked and induced gamma oscillations, and behavioral response data was the repeated measure ANOVA. Dependent ERP variables were amplitude of ERPs of interest at predetermined regions of interest (ROI). The withinparticipant factors were as follows: Stimulus (nontarget Kanizsat, target Kanizsa), Hemisphere (left, 
right), and Time (baseline, post-TMS) for the ASD group in rTMS treatment. Effects of TMS were analyzed using paired sample $t$-test. For baseline comparisons of the autistic and typical children the between-subject factor was Group (ASD, TD). Comparison of these two groups used independent sample $t$-test along with Levene's test for equality of variance. Post hoc analyses were conducted where appropriate. Reaction time (RT) and error rate (commission, omission, and total error rate) were analyzed using paired sample $t$-test. The same method was used for clinical behavioral rating scores. Histograms with normal distribution curves along with skewness and kurtosis data were obtained for each dependent variable to determine normality of distribution and appropriateness of data for ANOVA and $t$-tests. For more reliable determination of normality of distribution residual plots (i.e., normal probability plot and histogram versus fits and order) were created to indicate that treatment with ANOVA and $t$-test is justified. All dependent variables in the study had normal distribution. Greenhouse-Geisser correction on $p$ values were employed where appropriate in all ANOVAs. A priori hypotheses related to TMS effects were tested with the Student's $t$-tests for two groups with equal variance. Confidence intervals (95\% of mean, $[95 \% \mathrm{Cl}]$ ) were calculated for each RT, ERP, and gamma oscillation data sets entered for $t$-tests. For the estimation of the effect size and power in gamma oscillation analysis with ANOVA we used partial eta squared $\left(\eta^{2}\right)$ and observed power measures computed using $\alpha=0.05$ (Murphy \& Myors, 2004). SPSS 23.0 and Sigma Stat 3.1 statistical packages were used for analysis of data.

\section{Results}

\section{Behavioral responses (reaction time and} accuracy, post-error RT)

Baseline differences: ASD vs. TD. There were no differences in reaction time (RT) between ASD and TD groups. In total, the ASD group committed more errors as compared to controls $(10.0 \pm 12.51$ in ASD vs. $2.30 \pm 3.84 \%$ in TD group, $t=3.04, d f=43, p=$ $0.004)$. The differences in accuracy were mostly driven by differences in commission errors (mean difference $5.89 \pm 2.21 \%, t=2.63, d f=43, p=$ $0.011,95 \% \mathrm{Cl}$ from 1.38 to $10.27 \%$ ). The most pronounced difference between groups was found in post-error RT change $(52.45 \pm 12.51 \mathrm{~ms}, t=4.19, d f$ $=43, p<0.001,95 \% \mathrm{Cl}$ from 27.2 to $77.9 \mathrm{~ms}$ ). Control subjects showed normative post-error slowing (mean $28.9 \pm 47.6 \mathrm{~ms}$ ) while children with ASD did not show expected slowing but rather demonstrated speeding post-error $(-21.3 \pm 42.1$ $\mathrm{ms})$.

Effects of TMS. Effects of TMS on RT to targets were not significant. Accuracy post-TMS improved, as total error rate decreased by $5.52 \pm 14.04 \%, t=$ $2.08, d f=22, p=0.047$, though predominantly mediated by an improvement in commission error rate (mean decrease by $-5.22 \pm 12.36 \%, t=2.23$, $d f=22, p=0.034,95 \% \mathrm{Cl}-0.43$ to $-10.01 \%)$. Most significant effects of neuromodulation were found in the post-error RT change, in particular, pretreatment speeding changed into a normative post-error slowing (mean 24.5 $\pm 37.9 \mathrm{~ms}$ ) and difference was highly statistically significant $(45.89 \pm 51.43 \mathrm{~ms}, t=$ 4.72, $d f=22, p<0.001 ; 95 \% \mathrm{Cl}$ from 25.9 to 65.8 $\mathrm{ms})$.

\section{Response-locked frontal and frontocentral ERN} and $\mathrm{Pe}$

Three subjects from the TD group and two subjects from the ASD group at the baseline oddball test did not show sufficient number of commission errors and were excluded from the analysis. Therefore, comparison of ERN and $\mathrm{Pe}$ measures was conducted for 18 TD subjects and 20 ASD subjects. ASD and TD groups at the baseline test showed significant differences in ERN amplitude at ROI (five frontal and frontocentral sites) using $t$-test for independent samples (mean difference $3.99 \pm 1.42$ $\mu \mathrm{V}, t=2.82, d f=36, p=0.008,95 \% \mathrm{Cl}$ from 1.09 to $6.92 \mu \mathrm{V})$. Latency of ERN did not yield any statistically significant group differences. There were not found any between-group differences in amplitude and latency of $\mathrm{Pe}$ component.

Effects of rTMS. Paired sample $t$-test revealed statistically significant increase in negativity of the ERN amplitude at the frontal and frontocentral ROI post-TMS treatment in the ASD group (mean $4.89 \pm$ $5.50 \mu \mathrm{V}, t=3.62, d f=19, p=0.002,95 \% \mathrm{Cl}$ from 2.51 to $7.62 \mu \mathrm{V})$. Latency of the ERN decreased post-TMS (mean decrease $-27.5 \pm 44.6 \mathrm{~ms}, t=$ 2.61, $d f=19, p=0.018,95 \% \mathrm{Cl}$ from -5.28 to -49.7 $\mathrm{ms})$. Amplitude and latency of the $\mathrm{Pe}$ component did not show any post-TMS changes.

\section{Stimulus-locked ERP components Frontal and frontocentral ERP components.}

Frontal N100 at baseline. Amplitude of N100 was more negative to non-target stimuli in the ASD group than in the TD group, especially at the left hemisphere (mean difference $-1.27 \pm 0.55 \mu \mathrm{V}, t=$ 2.29, $d f=41, p=0.025,95 \% \mathrm{Cl}$ from -2.37 to -0.16 $\mu \mathrm{V}$, group sample variance was equal, $p=0.006$ ). N100 to targets was also more negative in the ASD 
group (at midline frontal sites, $-1.24 \pm 0.55 \mu \mathrm{V}, t=$ $2.25, d f=41, p=0.028,95 \% \mathrm{Cl}$ from -2.34 to -0.14 $\mu \mathrm{V}$; variance was equal, $p=0.003$ ).

Effects of rTMS on N100. TMS course had main effect on N100 amplitude $(F=4.69, p=0.049)$, but there were not found any interactions using Hemisphere (left, right) or Stimulus (non-target, target Kanizsa) and Time (pre-, post-TMS) factors. At the post-TMS test, N100 amplitude became less negative only to non-target Kanizsa stimuli (at the left frontocentral ROI by $1.34 \pm 1.95 \mu \mathrm{V} ; t=2.57$, $d f$ $=22, p=0.023,95 \% \mathrm{Cl}$ from 2.47 to $0.21 \mu \mathrm{V}$; while at the midline ROI only by $1.01 \pm 1.72 \mu \mathrm{V} ; t=2.21$, $d f=22, p=0.045$ ).
Frontal N200 at baseline and post-TMS. Amplitude of N200 component did not show any statistically significant differences between ASD and TD groups. We could not find any main effects of stimulus type or TMS factors, but post-TMS test did show statistically significant reduction of $\mathrm{N} 200$ to nontarget Kanizsa items (mean $1.38 \pm 2.52 \mu \mathrm{V}, t=2.33$, $d f=20, p=0.032,95 \% \mathrm{Cl}$ from 2.64 to $0.13 \mu \mathrm{V}$ ).

Frontal and frontocentral P300 (P3a) at baseline. Amplitude of P3a component was higher in the ASD group both to non-target and target Kanizsa stimuli (accordingly at midline in non-target condition by $2.66 \pm 1.19 \mu \mathrm{V}, t=2.23, d f=41, p=0.030,95 \% \mathrm{Cl}$ from 0.27 to $5.07 \mu \mathrm{V}$, equal variance at $p=0.05$; in target Kanizsa by $4.34 \pm 1.37 \mu \mathrm{V}, t=3.18, d f=41, p$ $=0.004,95 \% \mathrm{Cl}$ from 1.62 to $7.12 \mu \mathrm{V}$, equal variance test at $p=0.02$, see Figure 1).

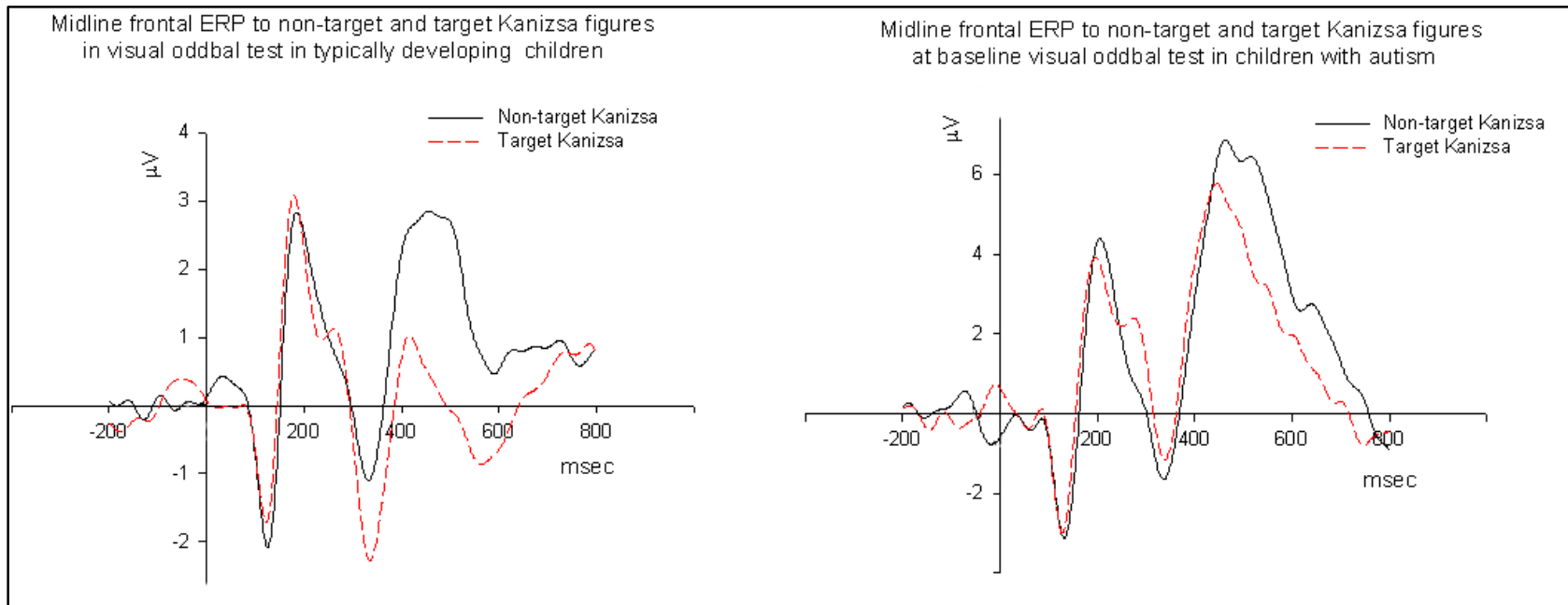

Figure 1. Midline frontal (Fz) ERPs to non-target and target Kanizsa illusory figures in the baseline visual oddball task in typically developing children $(N=21$, left) and in children with ASD $(N=23$, right). The ASD group shows higher amplitude of the $\mathrm{P} 3 \mathrm{a}$ components both to non-target and target Kanizsa figures.

Effects of rTMS on P3a. Post-TMS changes can be described as a decrease of $\mathrm{P} 3 \mathrm{a}$ amplitude to both non-target and target Kanizsa figures at all recording sites without any hemisphere or stimulus type interactions. TMS course had strong main effect on P3a amplitude $(F=10.14, p=0.004)$. Decrease of P3a amplitude at the midline frontal and frontocentral ROIs was significant (non-targets, $-2.03 \pm 3.28 \mu \mathrm{V}, t=2.96, d f=22, p=0.007,95 \% \mathrm{Cl}$ from -0.61 to $13.44 \mu \mathrm{V}$; targets, $-2.81 \pm 5.56 \mu \mathrm{V}, t=$ 2.42, $d f=22, p=0.024,95 \% \mathrm{Cl}$ from -0.41 to -5.21 $\mu \mathrm{V}$, see Figure 2). 


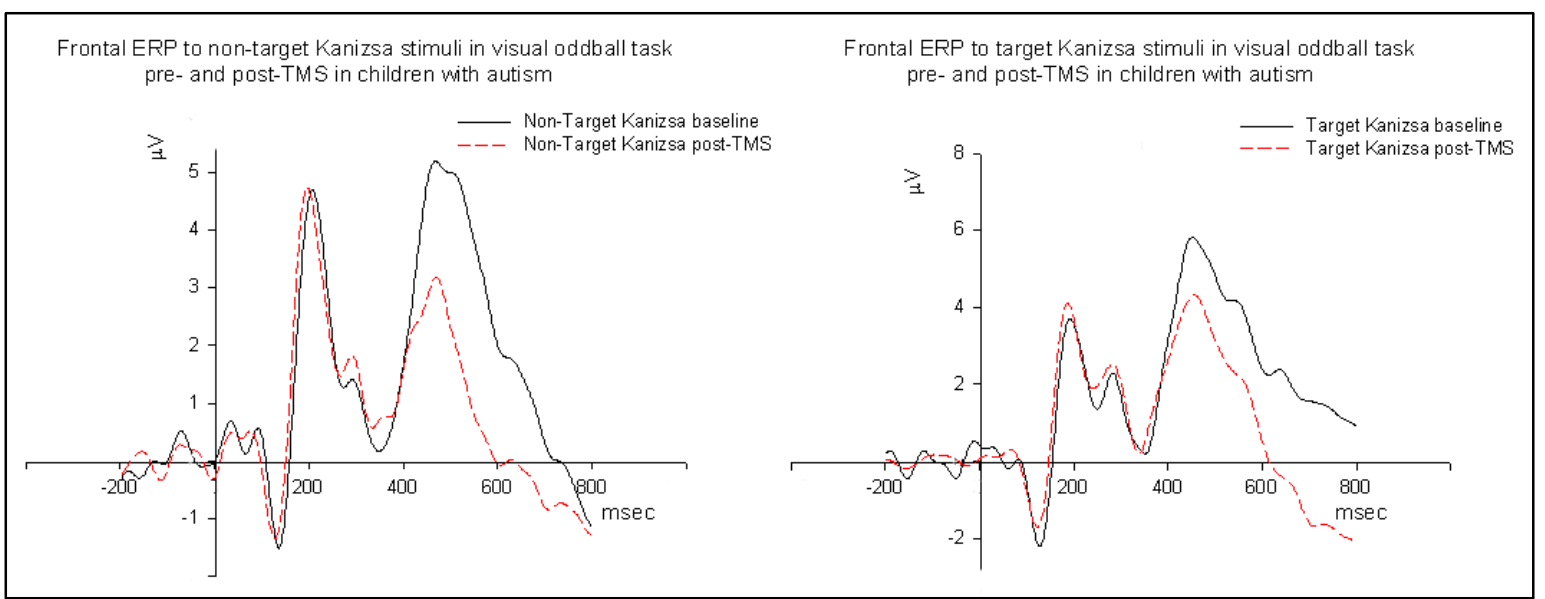

Figure 2. Left frontal ROI (F1, F3, F7) ERPs to non-target (left) and target (right) Kanizsa illusory figures at the baseline and post-TMS oddball tests in typically developing children $(N=21$, left) and in children with ASD ( $N=23$, right). The ASD group post-TMS shows lower amplitude of the P3a component to non-target and at a lesser extent to target Kanizsa figures.

Parietal and parieto-occipital ERP components. $P 100$ and P200. The only group difference in parietal and parieto-occipital P100 between ASD and TD groups was found in response to non-target Kanizsa stimuli, as it was of higher amplitude in the ASD group (mean $1.25 \pm 0.61 \mu \mathrm{V}, t=2.07, d f=41$, $p=0.042,95 \% \mathrm{Cl}$ from 0.04 to $2.45 \mu \mathrm{V}$; adjusted for unequal variance at $p=0.17$ ). TMS course had no main effects on P100 component's amplitude. There were not found any statistically significant post-TMS differences in P100 amplitude. Parietooccipital N200 component was more negative to targets in the ASD group (across both hemispheres by $-1.74 \pm 0.76 \mu \mathrm{V}, t=2.27, d f=41, p=0.026,95 \%$ $\mathrm{Cl}$ from -0.21 to $-3.28 \mu \mathrm{V}$; variance was equal at $p=$ $0.04)$.

Effects of rTMS. TMS procedure had main effect on posterior N200 amplitude $(F=7.31, p=0.014)$. Effect was primarily due to significant decrease of N200 post-TMS (across both hemispheres by -1.83 $\pm 2.72 \mu \mathrm{V}, t=3.08, d f=22, p=0.006,95 \% \mathrm{Cl}$ from -0.59 to $-3.07 \mu \mathrm{V}$ ) with effect being significant both at the left $(p=0.006)$ and the right $(p=0.017) \mathrm{ROIs}$, see Figure 3.
Parietal ERP to non-target Kanizsa stimuli in visual oddball task pre- and post-TMS course in children with austism

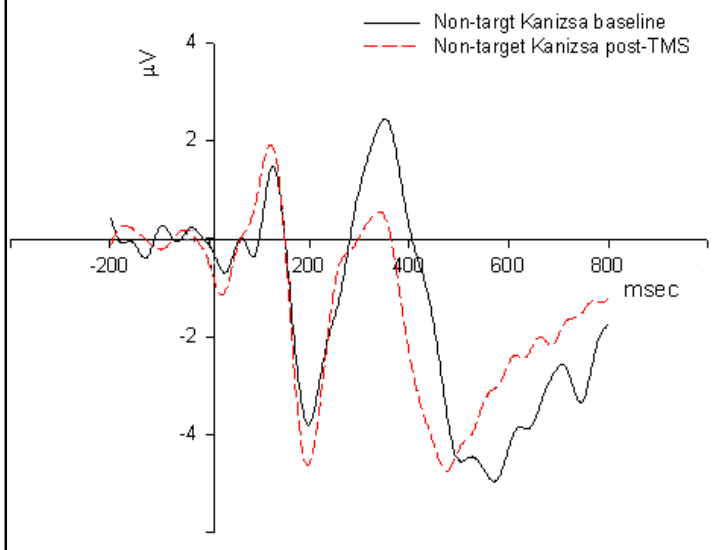

Parietal ERP to target Kanizsa stimuli in visual oddball task pre- and post-TMS course in children with autism

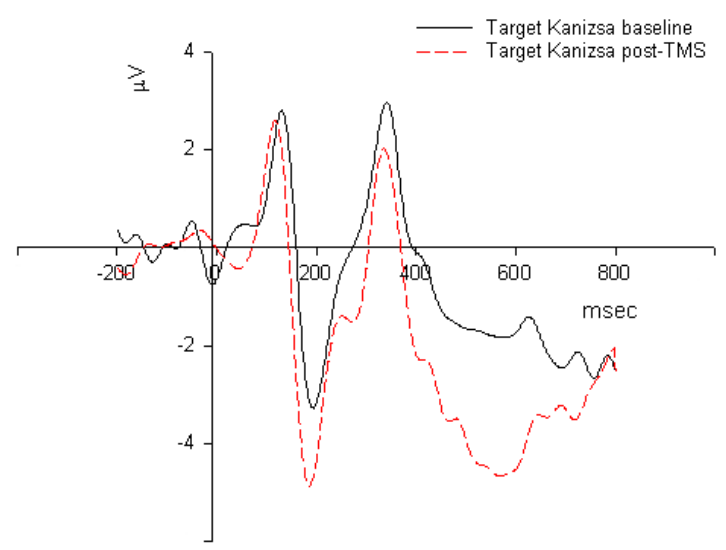

Figure 3. Bilateral parietal ROI (P3, P7, P4, P8) ERPs to non-target (left) and target (right) Kanizsa illusory figures at the baseline and post-TMS oddball tests in typically developing children $(N=21$, left $)$ and in children with ASD $(N=23$, right). The ASD group post-TMS shows lower amplitude of the N200 component to both non-target and target Kanizsa figures. 
Parietal $P 3 b$. There were no baseline differences in the parietal P300 (P3b) amplitude between ASD and TD, and the treatment with rTMS had only insignificant main effect on P3b response to target vs. non-target Kanizsa figures $(p=0.08)$. There were no other statistically significant outcomes to report regarding $\mathrm{P} 3 \mathrm{~b}$ amplitude.

\section{Evoked and induced gamma oscillations}

Evoked gamma at baseline. Mean amplitude of the early (evoked) gamma at the baseline test was higher in the ASD group to non-target Kanizsa figures at $\mathrm{F} 8$ site (by $0.91 \pm 0.39$ [standard error] $\mu \mathrm{V}$, $t=2.26, d f=41, \mathrm{p}=0.029,95 \% \mathrm{Cl}$ from 0.09 to
$1.70 \mu \mathrm{V}$; equal variance assumed at $p<0.001$ ), and also to target Kanizsa stimuli at F1 site (by $0.68 \pm$ $0.24 \mu \mathrm{V}, t=2.79, d f=41, p=0.008,95 \% \mathrm{Cl}$ from 0.19 to $1.17 \mu \mathrm{V}$, adjusted for non-equal variance at $p$ $=0.34$ ). Parietal evoked gamma responses showed similar tendency, slightly higher in the baseline test in the ASD group at P8 to non-targets $(0.82 \pm 0.41$ $\mu \mathrm{V}, t=2.01, d f=41, p=0.049,95 \% \mathrm{Cl}$ from 0.01 to $1.64 \mu \mathrm{V}$, equal variance at $p=0.002$ ), and barely reached significance at $\mathrm{P7}$ site to target Kanizsa figures $(0.64 \pm 0.32 \mu \mathrm{V}, t=2.01, d f=41, p=0.05$, $95 \% \mathrm{Cl}$ from 0.01 to $1.28 \mu \mathrm{V}$, equal variance at $p=$ 0.027 , see Figure 4).
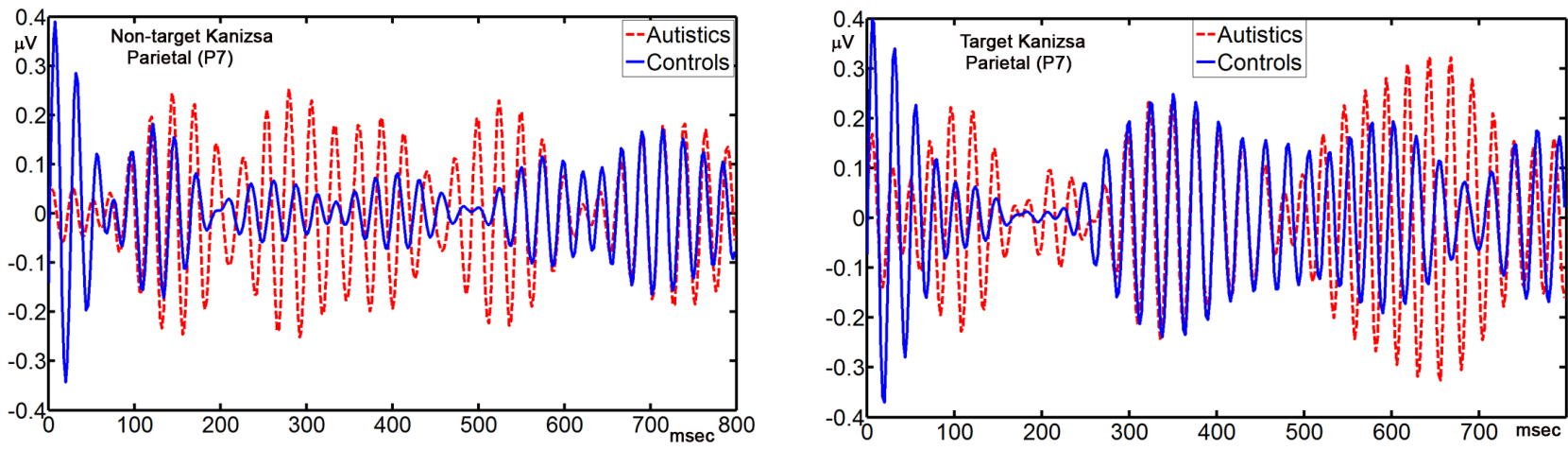

Figure 4. Evoked and induced gamma oscillations to non-target (left) and target (right) Kanizsa figures in a visual oddball task with illusory figures in ASD and TD groups of children. Grand averages of gamma responses in 23 children with ASD and 21 age- and gender-matched typical children at the left lateral parietal site (P7). The ASD group shows higher amplitude of the early evoked gamma (within 100-150 ms window poststimulus). Induced gamma to non-targets also was of higher amplitude in the ASD, while late gamma response to targets was not different those in control subjects within $250-450 \mathrm{~ms}$ window poststimulus, but shows tendency to increase 150-200 ms later.

Effects of TMS course on early gamma. Main effect of TMS on stimulus type factor (non-target vs. target Kanizsa) was significant both at the frontal (e.g., F7, F8; $F=9.18, p=0.005$ ) and parietal sites (e.g., P3, P4; $F=4.88, p=0.032$ ). Using repeated measure ANOVA most significant interactions were found for the inferior parietal $\mathrm{P} 7$ and $\mathrm{P} 8$ sites. Stimulus (non-target, target) $x$ Time (pre-, post-TMS) interaction was reaching significance level $(F=4.28$, $d f=1,41, p=0.045$, partial $\eta^{2}=0.097$, observed power $=0.52$ at $\alpha=0.05$ ) and can be described as a decrease of evoked gamma to only non-target Kanizsa stimuli post-TMS. Even more significant was Stimulus $\mathrm{X}$ Hemisphere $\mathrm{X}$ Time interaction $(F=$ 5.56, $d f=1,41, p=0.023$, partial $\eta^{2}=0.12$, observed power $=0.63$ at $\alpha=0.05$ ). Lateralization effect was characterized by more significant decrease of evoked gamma amplitude to nontargets at the left hemisphere post-TMS. Paired sample $t$-test showed decrease of evoked gamma to non-target Kanizsa figures at the frontal $\mathrm{F} 1$ site (by $-0.78 \pm 0.34 \mu \mathrm{V}, t=2.25, d f=22, p=0.029,95 \% \mathrm{Cl}$ from -0.08 to $-1.48 \mu \mathrm{V}$, equal variance test at $p=$ $0.014)$ and at the parietal P7 site $(-0.96 \pm 0.44 \mu \mathrm{V}, t$ $=2.18, d f=22, p=0.034,95 \% \mathrm{Cl}-0.07$ to -1.85 $\mu \mathrm{V}$, equal variance at $p=0.005$, see Figure 5). Amplitude of the evoked gamma at the parietal P4 site only tended to increase $(p=0.058)$.

Induced gamma at the baseline. Independent sample $t$-test with Levene's test for equality of variance did not reveal any group differences in late (induced) gamma other than higher induced gamma amplitude to non-target stimuli at P7 site in children 
with ASD (mean difference $0.85 \pm 0.41 \mu \mathrm{V}, t=2.09$, $d f=41, p=0.040,95 \% \mathrm{Cl}$ from 0.02 to $1.68 \mu \mathrm{V}$; adjusted assuming that sample had unequal variance at $p=0.45$ ). Induced gamma response at the same parietal site had tendency to be higher to target stimuli, but it reached significance only if window for analysis was expanded by additional 150 $\mathrm{ms}$ (up to $600 \mathrm{~ms}$ ). In such case amplitude of late gamma to target was significantly higher in the ASD group (mean difference $0.90 \pm 0.30 \mu \mathrm{V}, t=3.01, d f=$ $22, p=0.005,95 \% \mathrm{Cl}$ from 0.29 to $1.51 \mu \mathrm{V}$; variance of samples equal at $p=0.023$ ).

Effect of TMS course on late gamma. Main effect of rTMS on induced gamma amplitude was significant $(F=9.69, p=0.003)$. We found significant Stimulus (non-target, target) $X$ Hemisphere (left, right) $X$ Time

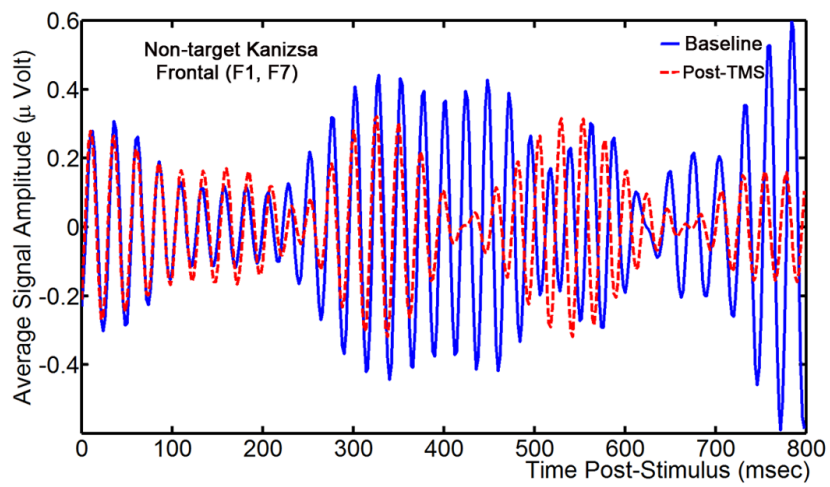

(pre-, post-TMS) interaction for the parietal P3-P4 sites $\left(F=6.21, d f=1,40, p=0.016\right.$, partial $\eta^{2}=$ 0.103 , observed power $=0.68$ at $\alpha=0.05$ ). The effect can be described as a more significant increase of late gamma oscillations to target Kanizsa figures at the left hemisphere. Eventually, only left parietal sites (P3, P7) showed significant increase post-TMS to targets using paired sample $t$-test (accordingly for P3- increase by $0.41 \pm 0.17 \mu \mathrm{V}, t=$ 2.34, $d f=22, p=0.023,95 \% \mathrm{Cl}$ from 0.06 to 0.77 $\mu \mathrm{V}$; for $\mathrm{P} 7,0.59 \pm 0.26 \mu \mathrm{V}, t=2.23, d f=22, p=0.03$, $95 \% \mathrm{Cl}$ from 0.06 to $1.13 \mu \mathrm{V}$ ). Left frontal F1 site also showed increase of induced gamma response to targets post-TMS $(0.33 \pm 0.16 \mu \mathrm{V}, t=2.05, d f=$ 22, $p=0.045,95 \% \mathrm{Cl}$ from 0.07 to $0.65 \mu \mathrm{V}$, see Figure 5).

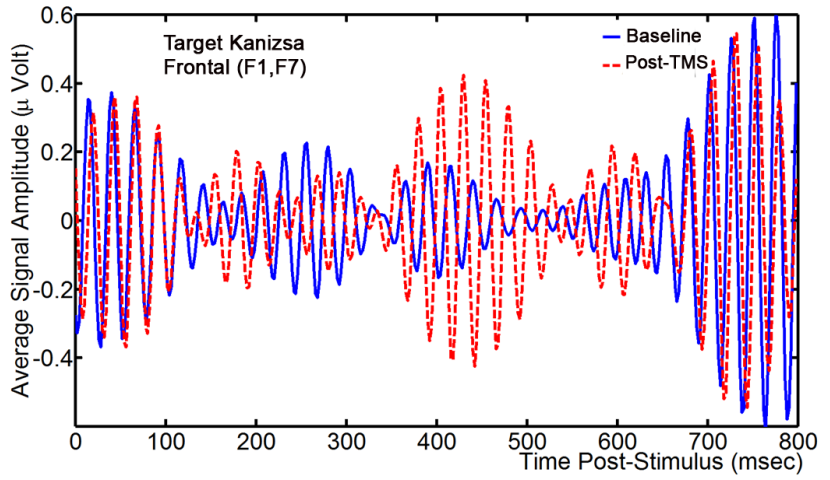

Figure 5. Evoked and induced gamma oscillations to non-target (left) and target (right) Kanizsa figures in a visual oddball task with illusory figures before and after 18 sessions of $1 \mathrm{~Hz}$ rTMS course in 23 children with ASD. Gamma oscillation response averaged across two frontal sites (F1 and F7) shows lower amplitudes of evoked gamma postTMS to non-targets, along with an increase of induced gamma oscillations amplitude to target stimuli. Main effect of TMS on induced gamma was significant.

\section{Clinical behavior evaluations post-TMS}

The Student's paired sample $t$-test showed a significant post-TMS reduction in Irritability subscale ratings as measured by the ABC (Aman, 2004; Aman \& Singh, 1994) from $10.39 \pm 7.82$ down to $7.87 \pm 6.27$ (i.e., decrease being $-2.52 \pm 5.22, t=$ 2.31, $d f=22, p=0.03 ; 95 \% \mathrm{Cl}$ from -0.26 to -4.78 ). Lethargy/Social Withdrawal and Hyperactivity subscales also showed statistically significant score reductions (Lethargy/Social Withdrawal, -1.65 \pm $3.73, t=2.21, d f=22,95 \% \mathrm{Cl}$ from -0.36 to -3.26 ; Hyperactivity, $-4.21 \pm 8.29, t=2.44, d f=22, p=$ $0.023,95 \% \mathrm{Cl}$ from -0.83 to -7.80$)$.
We found a significant decrease in stereotype, repetitive and restricted behavior patterns following rTMS course as measured by the RBS-R (Bodfish et al., 1999) and analyzed them using a paired sample Student's $t$-test. Total RBS-R score decreased from 21.65 to 17.61 , mean decrease being $-4.04 \pm 6.07, t$ $=3.19, d f=20, p=0.004,95 \% \mathrm{Cl}$ from -1.41 to -6.67. Both Stereotypic Behavior subscale and Ritualistic/Sameness behavior subscale scores showed significant decrease (accordingly $-0.78 \pm$ $1.75, t=2.13, d f=22, p=0.044,95 \% \mathrm{Cl}$ from -0.23 to -1.54 ; and $-1.30 \pm 2.24, t=2.78, d f=20, p=$ $0.011,95 \% \mathrm{Cl}$ from -0.33 to -2.27$)$. Compulsive behavior rating also decreased post-TMS $(-1.17 \pm$ 2.46, $t=2.28, d f=22, p=0.032,95 \% \mathrm{Cl}$ from -0.10 to -2.23 ). 


\section{Discussion}

Differences between ASD and TD children in RT, ERP and gamma band responses

In our study children with ASD did not differ from typical children in terms of reaction time, though they committed more errors, mostly commission errors, and did not show normative post-error RT slowing as TD children did. This is in concordance with our own prior results using this particular and other threestimuli type oddballs (Baruth, Casanova, Sears, et al., 2010; Sokhadze, Baruth, et al., 2009; Sokhadze, Baruth, El-Baz, et al., 2010) and with the majority of reaction time tests in children with ASD that note differences mostly in error rate and post-error correction function rather than reaction time (Baruth, Casanova, Sears, et al., 2010; Sokhadze et al., 2012). We proposed that deficits in error correction and impulsive key press may have connection with abnormality of error monitoring function, specifically reflected in lower magnitude of ERN (Sokhadze et al., 2012; Sokhadze, Baruth, Tasman, et al., 2010; Sokhadze, El-Baz, Sears, et al., 2014; Sokhadze, El-Baz, Tasman, et al., 2014). This difference in ERN amplitude was reported in several studies (Bogte, Flamma, van der Meere, \& van Engeland, 2007; Henderson et al., 2006; Thakkar et al., 2008; Vlamings, Jonkman, Hoeksma, van Engeland, \& Kemner, 2008) with indication that children and adult patients with ASD show reduced error processing capacity and deficient behavioral correction after an error is committed. This finding could be explained as a reflection of ASD patients' lower sensitivity to behavioral errors and/or reduced behavior correction ability. Most studies still agree with our finding that there are no differences in the $\mathrm{Pe}$ component between ASD and controls. After an error, ASD patients did not show accuracy improvement through post-error RT slowing as typical controls did. Normally, performance on the trials immediately after a committed error is improved as a result of a change in speed-accuracy strategy, which reflects executive control functioning (Burle, Possamaï, Vidal, Bonnet, \& Hasbroucq, 2002). The worsened post-error performance of ASD children suggests the presence of an executive control deficiency that may have important consequences in daily life as optimal error correction is necessary for adequate behavioral responses (Sokhadze, Baruth, Tasman, et al., 2010).

Frontal and frontocentral ERPs showed larger amplitude of exogenous N100 component to nontargets followed by prolonged latency and amplitude of the endogenous $\mathrm{P} 3 \mathrm{a}$ component in a similar way that we reported earlier using this oddball paradigm
(Sokhadze, Baruth, et al., 2009) and other types of novelty tasks (Baruth, Casanova, Sears, et al., 2010). At the posterior site we found increased P100 to non-targets almost at the same timing as anterior N100 increase to non-targets only. On the other hand, we could not find any P3b group differences. Children with autism diagnosis have been found to differ from typical children mainly with respect to the $\mathrm{P} 3 \mathrm{~b}$ in standard oddball tasks. Kemner and colleagues have reported an abnormally small occipital P3b in response to target visual stimuli (Kemner, van der Gaag, Verbaten, \& van Engeland, 1999; Kemner, Verbaten, Cuperus, Camfferman, \& van Engeland, 1994; Kemner, Verbaten, Cuperus, Camfferman, \& van Engeland, 1995). In autism the most consistent and frequently reported abnormality is $\mathrm{P} 3 \mathrm{~b}$ amplitude attenuation with auditory stimulus presentation (Bomba \& Pang, 2004; Bruneau, Roux, Adrien, \& Barthélémy, 1999; Oades, Walker, Geffen, \& Stern, 1988; Seri, Cerquiglini, Pisani, \& Curatolo, 1999; Townsend et al., 2001). However, in a simple visual target detection task there were no P3b amplitude differences found between autism and typical control subjects (Ciesielski, Courchesne, \& Elmasian, 1990; Courchesne, Lincoln, Yeung-Courchesne, Elmasian, \& Grillon, 1989). Our studies (Baruth et al., 2011; Baruth, Casanova, El-Baz, et al., 2010; Baruth, Casanova, Sears, et al., 2010; Casanova et al., 2012; Sokhadze et al., 2012; Sokhadze, Baruth, et al., 2009; Sokhadze, Baruth, Tasman, et al., 2010; Sokhadze, El-Baz, et al., 2009; Sokhadze, El-Baz, Sears, et al., 2014; Sokhadze, El-Baz, Tasman, et al., 2014) suggest that non-target responses (either ERP or evoked and induced gamma) in oddball paradigms should be routinely studied along with target responses in order to improve the diagnostic capabilities of cognitive ERPs. Notably, non-target responses may help to decide whether abnormal responses to target (e.g., induced gamma or P300) are related or not to a deficit in the mobilization of attentional resources (García-Larrea, Lukaszewicz, \& Mauguière, 1992).

We found higher amplitude of both evoked and induced gamma oscillations in children with ASD to non-target illusory figures both at the left frontal and parietal sites, and tendency to higher induced gamma only if analysis included more delayed burst of late gamma. Deviations from typical gamma-band activity have been reported in several studies on neurological disorders, including epilepsy, Alzheimer's disease, ADHD, and autism (Herrmann \& Demiralp, 2005). Individuals with ASD experience atypical visual perception, yet the etiology of this 
phenomenon still remains not sufficiently well studied (Milne et al., 2009).

Our prior studies (Baruth et al., 2011; Sokhadze, ElBaz, et al., 2009) indicated that individuals with autism had a minimal difference in evoked gamma power between target and non-target Kanizsa stimuli at all EEG channels of interest. In fact, evoked gamma power responses were slightly larger in response to non-target Kanizsa stimuli relative to targets. In contrast, the control group had a significantly higher evoked gamma power to target Kanizsa stimuli compared to non-target Kanizsa stimuli showing clear differences in visual stimulus discrimination. Additionally, the control group showed a greater difference in evoked gamma power between frontal and parietal regions to all stimuli over the left hemisphere: controls had more frontal as compared to parietal gamma activity, while the ASD group showed negligible topographic differences.

These findings are similar to the findings of Grice et al. (2001) where individuals with autism did not show significant differences in frontal gamma activity during the processing of upright and inverted faces, whereas control subjects showed clear discriminative increases in frontal gamma activity when the faces were presented upright vs. inverted. These findings also correspond to our previous investigation (Sokhadze, El-Baz, et al., 2009) where we found positive differences in gamma oscillation power (i.e., $30-80 \mathrm{~Hz}, \quad 0-800 \mathrm{~ms}$ poststimulus) between target and non-target Kanizsa stimuli were decreased, especially over the lateral frontal (F7, F8) and parietal (P7, P8) EEG sites, in adolescents and young adults with autism; this was mainly due to significant increases in gamma power at all recording sites, especially evoked gamma (i.e., approximately 100 milliseconds) over frontal channels, to non-target Kanizsa stimuli. Our results indicated that in ASD evoked gamma activity is not discriminative of stimulus type, whereas in controls early gamma power differences between target and non-target stimuli are highly significant.

There are a few plausible explanations as to why the gamma response does not allow for discrimination between stimuli in ASD. It is well known that ASD is associated with amplified responses to incoming sensory information. Studies suggest that the neural systems of individuals with ASD are overactivated (Belmonte \& Yurgelun-Todd, 2003a, 2003b), and there is a lack of cortical inhibitory tone (Casanova et al., 2006; Casanova, Buxhoeveden, Switala, et al., 2002a, 2002b; Rubenstein \& Merzenich, 2003).
In a network that is overactivated and 'noisy', local cortical connectivity may be enhanced at the expense of long-range cortical connections, and individuals with ASD may have difficulty directing attention. It may not be possible for them to selectively activate specific perceptual systems based on the relevance of a stimulus (i.e., target vs. non-target).

The topic of neural and functional connectivity abnormalities was always considered as an extremely important one in current autism neuropathology theories (Belmonte et al., 2004; Courchesne \& Pierce, 2005; Just et al., 2004; Minshew \& Williams, 2007; Welchew et al., 2005). Some authors consider autism a disorder of neural connectivity (Coben et al., 2013). The modern theoretical view suggests that autism reflects a global processing neurodevelopmental defect produced by an excessive local connectivity and deficient distal connectivity resulting in functional disconnectivity of networks important in behavior and social cognition. The combination of local sensory hyperarousal and low-level overprocessing of incoming sensory stimuli, and at the same time abnormalities in attention selectivity and focus, according to Baron-Cohen and Belmonte (2005) may tap at the overconnected low-level processing neural networks in autism spectrum disorders. In such overwired networks, signal is insufficiently differentiated from noise or task-irrelevant information and as a result information processing capacity is drastically reduced (Belmonte \& Yurgelun-Todd, 2003a, 2003b; Rubenstein \& Merzenich, 2003). The brain's limited long-range wiring cannot directly sustain coordinated activity across arbitrary cortical locations, but it can convey patterns of synchronous activity as oscillatory neuronal fluxes, represented by local field potentials measured by EEG. Coordination of EEG oscillations at varying interacting frequencies allows for relatively efficient and unconstrained segregation in varying forms and across hierarchical cortical levels. Longrange abnormal neural connectivity model is suggested to explain dysfunctions deficits in highlevel complex information processing functions where rapid and integrated operation of many separate neural systems is required (Brock et al., 2002; Minshew, Goldstein, \& Siegel, 1997; Welchew et al., 2005).

Gamma response as such represents attentionrelated processes: it reflects stimulus evaluation and response selection activity related to different stages of information processing. Furthermore, since the evoked gamma oscillations to the target illusory 
figure, the deviant illusory figure, and the standard nonillusory stimuli were similar in response amplitude and relative power, the early gamma oscillation could be even considered as an attention-trigger process that gives information about the arrival of a stimulus and about the need for more detailed processing that is occurring later in time and is reflected in cognitive ERP (N200, P300) and late (induced) gamma response.

The gamma frequencies, particularly those centered about $40 \mathrm{~Hz}$, have been tied to visual, attentional, cognitive, and memory processes (Başar et al., 2001). Functional mechanisms of oscillatory activity in the gamma frequency range detected in various studies in animal models (Gray et al., 1989) and human electroencephalogram (EEG; Başar et al., 2001; Herrmann et al., 2004; Herrmann \& Demiralp, 2005; Herrmann \& Mecklinger , 2001; Tallon-Baudry et al., 1996) and magnetoencephalogram (Herrmann \& Knight, 2001; Port et al., 2015; Tallon-Baudry, 2003; Tallon-Baudry et al., 2005; Tallon-Baudry, Bertrand, Peronnet, \& Pernier, 1998) include perceptual feature binding, memory, object representation, and attentional processes (Böttger, Herrmann, \& von Cramon, 2002; Padmanabhapillai et al., 2006). The studies of oscillatory responses in gamma-band activity proved to be very useful in understanding of the mechanisms how brain processes information (Başar et al., 2001).

\section{Effects of rTMS on behavior, ERP, and gamma responses in children with ASD}

Effects of rTMS on behavioral measures of performance in oddball tasks were manifested in reduced error rate, mostly due to lower commission errors and in significant improvement of the normative post-error reaction time slowing. Response-locked ERN increase pointed to more efficient motor error detection. We already reported similar results on improvement of accuracy of behavioral responses and improvement in errormonitoring function in children with autism in our prior studies using rTMS (Sokhadze et al., 2012; Sokhadze, El-Baz, Sears, et al., 2014). It should be noted that in our prior studies we also could not find any changes in the $\mathrm{Pe}$ component post-TMS. Posttreatment changes in anterior ERPs were featured mostly in decrease of the frontal negativities (N100, N200) only to non-target Kanisza figures, along with decrease of the P3a amplitude both to target and non-target stimuli. Posterior EEG sites showed decrease of the parietal N200 amplitude to targets bilaterally, but no changes were found in the P3b amplitude. Since there were no other studies using ERP as outcomes of rTMS treatment reported to date, we could only compare these ERP outcomes with our prior studies using similar rTMS with posttreatment assessment ERP outcomes (Baruth et al., 2011; Casanova et al., 2012; Casanova \& Sokhadze, 2014; Sokhadze et al., 2012; Sokhadze, Baruth, Tasman, et al., 2010; Sokhadze, El-Baz, et al., 2009; Sokhadze, El-Baz, Sears, et al., 2014; Sokhadze, El-Baz, Tasman, et al., 2014). The outcomes of behavioral evaluations using RBS-R (Bodfish et al., 1999) and ABC (Aman \& Singh, 1994) questionnaires showed improvements in autism symptoms (e.g., irritability and hyperactivity on $A B C$; stereotype and repetitive behaviors on RBS) similar to those that we reported in our other study when 18-sessions-long 1 - Hz rTMS course was used in 27 children with ASD (Sokhadze, El-Baz, Sears, et al., 2014) and in a study where rTMS was combined with 18 sessions of neurofeedback training (Sokhadze, El-Baz, Tasman et al., 2014).

One of the most important goals of this study was the analysis of evoked and induced gamma oscillation changes post-TMS course in children with autism. We detected significant TMS effects on early gamma oscillations on non-target stimuli, in particular, a decrease of amplitude of evoked gamma post-TMS. In addition, we found a lateralization effect which can be described as a more significant decrease at the left hemisphere, both at the frontal and parietal sites. Effects of rTMS course on induced gamma were manifested in an increase of late gamma oscillations in response to target Kanizsa figures. This effect was more pronounced at the left parietal sites. There is a certain concordance with our ERP findings (mostly frontal N100 and N200, and parietal N200 changes) though we did not make any attempt to analyze correlations between gamma oscillation responses and specific ERP components. For the purpose of this study it was sufficient to see that the main changes of both type responses were occurring in the same time window and probably were reflecting different aspects of the same attentional, perceptual, and cognitive processes.

We can consider several mechanisms contributing to the normalization of initially excessive sensory reactivity (e.g., higher magnitude of exogenous ERPs and higher evoked gamma) following inhibitory rTMS treatment course in children with autism. As it was already noted by Belmonte and Yurgelun-Todd (2003a, 2003b), perceptual filtering of incoming stimulation in autism is thought to occur in an "all-or-none" mode without relevance to task specificity for the stimulus. The attention in 
individuals with autism seems to be dependent more on the coarse control of general arousal than on selective activation of specific sensory systems. Abnormalities of arousal control and their role in atypical attention style in ASD was noted also by other authors (Orekhova \& Stroganova, 2014). It is reasonable to suggest that active inhibition of irrelevant distractors, or in other words normative habituation, is not properly functioning and allows both task-relevant and task-irrelevant stimuli to pass through earlier filtering processes creating an overload on later stages of stimulus processing. It was outlined by several studies that an increased ratio of excitation/inhibition in cortical systems and high "cortical noise" have been considered one of the core abnormalities in autism (Casanova et al., 2003; Rubenstein \& Merzenich, 2003; Uzunova et al., 2015). In this current study we used slow rTMS over the DLPFC of children with ASD in our continuing efforts to increase the inhibitory surround of minicolumns in this prefrontal area. Due to the phenomenon of diaschisis and the connectivity of this brain region we expected the intervention not to be limited only to the site of magnetic stimulation (e.g., DLPFC) but rather to generalize to other cortical areas.

A focal electrical current induced by rTMS orthogonal to the pial surface results in a short-term functional reorganization of cortical activity. Since the effects of rTMS are not limited to the stimulated target cortex but give rise to functional changes in anatomically and functionally interconnected cortical areas, rTMS can strengthen functional connectivity between cortical areas. Low-frequency rTMS has been reported to operate via long-term depression of cortical activity (Hoffman \& Cavus, 2002), which we hypothesize preferentially activates radially-oriented double-bouquet axons. Current findings of postTMS improvement in executive functions such as error monitoring, more effective detection of target, less distraction to non-target items processing, etc. may add new insight to understanding of neuropathological mechanisms underlying ASD symptoms. We showed that treatment with rTMS decreased excess gamma activity to non-target distractors and amplified ERP and gamma responses to target items in ASD patients during visual task, thus improving the signal differentiation between processing relevant and irrelevant lllusory stimuli. Additionally, it seems that rTMS improved the activity at different regions of the brain (e.g., frontal and parietal cortices) and significantly improved repetitive and restricted behavior patterns associated with ASD assessed using clinical behavior evaluation instruments. Our results suggest that low-frequency rTMS may improve the inhibitory tone and decrease the ratio of cortical excitation to inhibition in ASD. This may lead to improved long-range connectivity within prefrontal and midfrontal mesial cortical structures and also along fronto-parietal attention networks. In describing the presence of a minicolumnopathy in autism, our group gave as predictive validity possible alterations in the blueprint of white matter connectivity, gamma frequency abnormalities, and the use of low-frequency (inhibitory) rTMS as a possible therapeutic intervention (Casanova, Buxhoeveden, \& Brown, 2002; Casanova et al., 2012, 2015; Casanova \& Sokhadze, 2014; Sokhadze, Casanova, \& Baruth, 2013; Sokhadze, El-Baz, et al., 2009). These predictions were based, in part, on the compartmentalization of minicolumnar abnormalities in the peripheral neuropil space across all different laminae of the cerebral cortex. The resultant defect in lateral inhibition has now been proven using EEG and responses to tactile vibratory stimuli (Kéïta, Mottron, Dawson, \& Bertone, 2011; Puts, Wodka, Tommerdahl, Mostofsky, \& Edden, 2014; Tavassoli et al., 2016).

There are several limitations that should be mentioned: the design of the project does not incorporate a control group with rTMS treatment as the Institutional Review Board prohibited active treatment in typically developing children. In this regard we could be criticized that the study represents a case series study rather than a controlled study. The only type of control we used was a comparison of behavioral, ERP, and gamma responses at the baseline stage between children with ASD and typically developing children that served as a contrast group. The outcomes of the rTMS part of the study were not controlled. In the past we did a wait-list controlled trial using similar rTMS regimen (Baruth et al., 2011; Casanova et al., 2012; Sokhadze et al., 2012; Sokhadze, El-Baz, Sears, et al., 2014; Sokhadze, El-Baz, Tasman, et al., 2014) and now prepare to conduct sham-TMScontrolled, randomized clinical trial. The current study should therefore be considered as exploratory in nature and aimed at selecting target EEG gamma and ERP outcomes to refine them in future studies. This explains also our decision to use and report outcomes of only a limited number of behavioral and clinical questionnaires, as our focus was first of all on electrophysiological markers and outcomes.

Our study did not compare evoked and induced responses of frequencies other than gamma, and we did not analyze cross-frequency coupling of gamma band with other EEG frequencies; this can be 
considered as yet another limitation. Gamma oscillations are known to be involved in various cognitive processes and are considered by many researchers as carrying fundamental functions for information processing within the brain. While gamma oscillations, specifically those evoked in response to stimulation like in our study, have been shown to correlate with other EEG rhythms and evoked oscillation in different frequency ranges, to date there have been few empirically supported evidence presented to support a casual influence of gamma oscillations on other EEG rhythms. For instance, Grosse-Wentrup, Schölkopf, and Hill (2011) presented results supporting relations of gamma oscillations and sensorimotor rhythm (SMR) in healthy subjects during motor imagery, in particular positive correlation of SMR with gamma power at the frontal-occipital and negative correlation at the centroparietal sites.

There is an important methodological issue that refers to the interpretation of topographical distributions in studies in which 128-channel montages were used. The problem is the selection of the EEG reference for analysis (Müller et al., 2000). In our studies we used $\mathrm{Cz}$ as reference and did not try to transform the $\mathrm{Cz}$ recording reference to the average reference prior to wavelet analysis. As with every choice of a nonactive reference, the question arises as to whether our findings with respect to a given electrode reflect activity of the cortex under that electrode topography or result from potentials variations of the reference. For example, it has been argued that the average reference may produce so-called 'ghost fields' and can produce distortions of focal features (Desmedt \& Tomberg, 1990; Desmedt, Tomberg, Noël, \& Ozaki, 1990) when applied to time-locked signals. It seems likely that this is also possible with induced responses. While some alternate approaches (e.g., the use of spline Laplacians) may overcome reference electrode and some other problems, they may act as a form of spatial filtering and underestimate actual gamma response values.

Analysis of evoked and induced EEG gamma oscillations could provide for important outcome measures, a potential cortical "fingerprint," of activation patterns associated with core behavioral and cognitive abnormalities that characterize ASD. Furthermore, when analyzed along with behavioral (reaction time, accuracy, etc.) and event-related potential data, the gamma-oscillations-based biomarkers will offer insights into the psychophysiology of ASD. The relative low cost of EEG methods means that the proposed biomarker will be accessible to many individuals and to those studies requiring large samples. EEG modalities are noninvasive and can be tolerated by many individuals who would otherwise not be able to participate in alternative studies, for example, runctional magnetic resonance imaging (fMRI).

\section{Author Notes}

The study was partially supported by National Institutes of Health Eureka R01 grant R01MH86784 to Manuel F. Casanova and National Science Foundation of China grant 61273063 to Xiaoli Li.

\section{References}

Aman, M. G. (2004). Management of hyperactivity and other acting-out problems in patients with autism spectrum disorder. Seminars in Pediatric Neurology. 11(3), 225-228. http://dx.doi.org/10.1016/j.spen.2004.07.006

Aman, M. G., \& Singh, N. N. (1994). Aberrant Behavior Checklist-Community. Supplementary Manual. East Aurora, NY: Slosson Educational Publications.

American Psychiatric Association. (2000). Diagnostic and Statistical Manual of Mental Disorders (4th ed., text rev.). Washington, DC: Author.

Baron-Cohen, S., \& Belmonte, M. K. (2005). Autism: a window onto the development of the social and the analytic brain. Annual Review of Neuroscience, 28, 109-126. http://dx.doi.org/10.1146/annurev.neuro.27.070203.144137

Baruth, J. M., Casanova, M. F., El-Baz, A., Horrell, T., Mathai, G., Sears, L., \& Sokhadze, E. (2010). Low-frequency repetitive transcranial magnetic stimulation modulates evoked-gamma frequency oscillations in autism spectrum disorders. Journal of Neurotherapy, 14(3), 179-194. http://dx.doi.org/10.1080 /10874208.2010.501500

Baruth, J. M., Casanova, M. F., Sears, L., \& Sokhadze, E. (2010). Early-stage visual processing abnormalities in highfunctioning autism spectrum disorder (ASD). Translational Neuroscience, 1(2), 177-187. http://dx.doi.org/10.2478 /v10134-010-0024-9

Baruth, J., Williams, E., Sokhadze, E., El-Baz, A., Sears, L., \& Casanova, M.F. (2011). Repetitive transcranial stimulation (rTMS) improves electroencephalographic and behavioral outcome measures in autism spectrum disorders (ASD). Autism Science Digest, 1(1), 52-57.

Başar, E. (1980). EEG brain dynamics: Relation between EEG and brain evoked potentials. Amsterdam: Elsevier.

Başar, E., Schürmann, M., Başar-Eroglu, C., \& Demiralp, T. (2001). Selectively distributed gamma band system in brain. International Journal of Psychophysiology, 39(2-3), 129-135.

Belmonte, M. K., \& Yurgelun-Todd, D. A. (2003a). Anatomic dissociation of selective and suppressive processes in visual attention. Neurolmage, 19(1), 180-189. http://dx.doi.org /10.1016/S1053-8119(03)00033-8

Belmonte, M. K., \& Yurgelun-Todd, D. A. (2003b). Functional anatomy of impaired selective attention and compensatory processing in autism. Cognitive Brain Research, 17(3), 651664. http://dx.doi.org/10.1016/S0926-6410(03)00189-7

Belmonte, M. K., Allen, G., Beckel-Mitchener, A., Boulanger, L. M., Carper, R. A., \& Webb, S. J. (2004) Autism and abnormal development of brain connectivity. Journal of Neuroscience, 24(42), 9228-9231. http://dx.doi.org/10.1523 IJNEUROSCI.3340-04.2004

Bertrand, O., \& Tallon-Baudry, C. (2000). Oscillatory gamma activity in humans: A possible role for object representation. International Journal of Psychophysiology, 38(3), 211-223. http://dx.doi.org/10.1016/S0167-8760(00)00166-5 
Bodfish, J. W., Symons, F. J., \& Lewis, M. H. (1999). Repetitive behavior scales. Morgantown, NC: Western Carolina Center Research Reports.

Bodfish, J. W., Symons, F. J., Parker, D. E., \& Lewis, M. H. (2000). Varieties of repetitive behavior in autism: Comparisons to mental retardation. Journal of Autism and Developmental Disorders, 30(3), 237-243.

Bogte, H., Flamma, B., van der Meere, J., \& van Engeland, H. (2007). Post-error adaptation in adults with high functioning autism. Neuropsychologia, 45(8), 1707-1714. http://dx.doi.org /10.1016/j.neuropsychologia.2006.12.020

Bomba, M. D., \& Pang, E. W. (2004) Cortical auditory evoked potentials in autism: A review. International Journal of Psychophysiology, 53(3), 161-169. http://dx.doi.org/10.1016 /j.ijpsycho.2004.04.001

Böttger, D., Herrmann, C. S., \& von Cramon, D. Y. (2002) Amplitude differences of evoked alpha and gamma oscillations in two different age groups. International Journal of Psychophysiology, 45(3), 245-251. http://dx.doi.org /10.1016/S0167-8760(02)00031-4

Brock, J., Brown, C. C., Boucher, J., \& Rippon, G. (2002). The temporal binding deficit hypothesis of autism. Development and Psychopathology, 14(2), 209-224. http://dx.doi.org /10.1017/S0954579402002018

Brown, C. (2005). EEG in autism: Is there just too much going on in there? In M. F. Casanova (Ed.), Recent developments in autism research (pp. 109-126). New York: Nova Science Publishers.

Brown, C., Gruber, T., Boucher, J., Rippon, G., \& Brock, J. (2005). Gamma abnormalities during perception of illusory figures in autism. Cortex, 41(3), 364-376.

Bruneau, N., Roux, S., Adrien, J. L., \& Barthélémy, C. (1999) Auditory associative cortex dysfunction in children with autism: Evidence from late auditory evoked potentials (N1 wave-T Complex). Clinical Neurophysiology, 110(11), 19271934. http://dx.doi.org/10.1016/S1388-2457(99)00149-2

Burle, C., Possamaï, C.-A., Vidal, F., Bonnet, M., \& Hasbroucq, T. (2002). Executive control in the Simon effect: An electromyographic and distributional analysis. Psychological Research, 66(4), 324-336. http://dx.doi.org/10.1007/s00426002-0105-6

Cantor, D. S., Thatcher, R. W., Hrybyk, M., \& Kaye, H. (1986). Computerized EEG analysis of autistic children. Journal of Autism and Developmental Disorders, 16(2), 169-187. http://dx.doi.org/10.1007/BF01531728

Casanova, M. F., Baruth, J., El-Baz, A. S., Sokhadze, G. E., Hensley, M., \& Sokhadze, E. M. (2013). Evoked and induced gamma-frequency oscillation in autism. In M. F. Casanova, A. S. El-Baz, and J. S. Suri (Eds.), Imaging the Brain in Autism (pp. 87-106). New York: Springer. http://dx.doi.org/10.1007 /978-1-4614-6843-1

Casanova, M. F., Baruth, J. M., El-Baz, A., Tasman, A., Sears, L., \& Sokhadze, E. (2012). Repetitive transcranial magnetic stimulation (rTMS) modulates event-related potential (ERP) indices of attention in autism. Translational Neuroscience, 3(2), 170-180. http://dx.doi.org/10.2478/s13380-012-0022-0

Casanova, M. F., Buxhoeveden, D. P., \& Brown, C. (2002c). Clinical and macroscopic correlates of minicolumnar pathology in autism. Journal of Child Neurology, 17(9), 692695. http://dx.doi.org/10.1177/088307380201700908

Casanova, M. F., Buxhoeveden, D., \& Gomez, J. (2003). Disruption in the inhibitory architecture of the cell minicolumn Implications for autism. The Neuroscientist, 9(6), 496-507. http://dx.doi.org/10.1177/1073858403253552

Casanova, M. F., Buxhoeveden, D. P., Switala, A. E., \& Roy, E. (2002a). Minicolumnar pathology in autism. Neurology, 58(3), 428-432. http://dx.doi.org/10.1212/WNL.58.3.428

Casanova, M. F., Buxhoeveden, D. P., Switala, A. E., \& Roy, E. (2002b). Neuronal density and architecture (gray level index) in the brains of autistic patients. Journal of Child Neurology,
$17(7)$, $515-521$.

http://dx.doi.org/10.1177 /088307380201700708

Casanova, M. F., \& Sokhadze, E. M. (2014). Transcranial magnetic stimulation: Application in autism treatment. In V. W. Hu (Ed.), Frontiers in autism research: New horizons for diagnosis and treatment (pp. 583-606). Hackensack, NJ: World Scientific Publishing Co.

Casanova, M. F., Sokhadze, E., Opris, I., Wang, Y., \& Li, X. (2015). Autism spectrum disorders: Linking neuropathological findings to treatment with transcranial magnetic stimulation. Acta Paediatrica, 104(4), 346-355. http://dx.doi.org/10.1111 lapa.12943

Casanova, M. F., van Kooten, I. A. J., Switala, A. E., van Engeland, H., Heinsen, H., Steinbusch, H. W. M., ... Schmitz, C. (2006). Abnormalities of cortical minicolumnar organization in the prefrontal lobes of autistic patients. Clinical Neuroscience Research, 6(3-4), 127-133. http://dx.doi.org/10.1016/j.cnr.2006.06.003

Ciesielski, K. T., Courchesne, E., \& Elmasian, R. (1990). Effects of focused selective attention tasks on event-related potentials in autistic and normal individuals. Electroencephalography and Clinical Neurophysiology, 75(3), 207-220.

Clark, V. P., Fan, S., \& Hillyard, S. A. (1995). Identification of early visual evoked potential generators by retinotopic and topographic analyses. Human Brain Mapping, 2(3), 170-187. http://dx.doi.org/10.1002/hbm.460020306

Coben, R., Chabot, R. J., \& Hirshberg, L. (2013). EEG analyses in the assessment of autistic disorders. In M. F. Casanova, A. S. $\mathrm{El-Baz}$, and J. S. Suri (Eds.), Imaging the Brain in Autism (pp. 349-370). New York: Springer. http://dx.doi.org/10.1007/9781-4614-6843-1_12

Coben, R., Clarke, A. R., Hudspeth, W., \& Barry, R. J. (2008). EEG power and coherence in autistic spectrum disorder. Clinical Neurophysiology, 119(5), 1002-1009. http://dx.doi.org /10.1016/j.clinph.2008.01.013

Coles, M. G. H., \& Rugg, M. D. (1995). Event-related brain potentials: An introduction. In M. D. Rugg \& M. G. H. Coles, (Eds.), Electrophysiology of mind: Event-related brain potentials and cognition (pp. 40-85). Oxford: Oxford University Press.

Cornew, L., Roberts, T. P. L., Blaskey, L., \& Edgar, J. C. (2012). Resting-state oscillatory activity in autism spectrum disorders. Journal of Autism and Developmental Disorders, 42(9), 18841894. http://dx.doi.org/10.1007/s10803-011-1431-6

Courchesne, E., Lincoln, A. J., Yeung-Courchesne, R., Elmasian, R. \& Grillon, C. (1989). Pathophysiologic findings in nonretarded autism and receptive developmental language disorder. Journal of Autism and Developmental Disorders, 19(1), 1-17. http://dx.doi.org/10.1007/BF02212714

Courchesne, E., \& Pierce, K. (2005) Why the frontal cortex in autism might be talking only to itself: Local over-connectivity but long-distance disconnection. Current Opinion in Neurobiology. 15(2), 225-230. http://dx.doi.org/10.1016 /j.conb.2005.03.001

Croarkin, P. E., Wall, C. A., \& Lee, J. (2011). Applications of transcranial magnetic stimulation (TMS) in child and adolescent psychiatry. International Review of Psychiatry, 23(5), 445-453. http://dx.doi.org/10.3109 109540261.2011.623688

C2 multichannel physiological monitoring device [Apparatus]. Poulsbo, WA: J\&J Engineering, Inc.

Daskalakis, Z. J., Christensen, B. K., Fitzgerald, P. B., \& Chen, R. (2002). Transcranial magnetic stimulation: A new investigational and treatment tool in psychiatry. The Journal of Neuropsychiatry and Clinical Neurosciences, 14(4), 406415. http://dx.doi.org/10.1176/jnp.14.4.406

Desmedt, J. E., \& Tomberg, C. (1990). Topographic analysis in brain mapping can be compromised by the average 
reference. Brain Topography, 3(1), 35-42. http://dx.doi.org /10.1007/BF01128859

Desmedt, J. E., Tomberg, C., Noël, P., \& Ozaki, I. (1990). Beware of the average reference in brain mapping. Electroencephalography and Clinical Neurophysiology, Suppl. $41,22-27$.

Donner, T. H., \& Siegel, M. (2011). A framework for local cortical oscillation patterns. Trends in Cognitive Sciences, 15(5), 191-199. http://dx.doi.org/10.1016/j.tics.2011.03.007

EGI system [Apparatus]. Eugene, OR: Electrical Geodesics, Inc.

Engel, A. K., \& Singer, W. (2001). Temporal binding and the neural correlates of sensory awareness. Trends in Cognitive Sciences, 5(1), 16-25. http://dx.doi.org/10.1016/S13646613(00)01568-0

E-Prime (Version 1.0) [Computer software]. Sharpsburg, PA: Psychology Software Tools, Inc.

Fell, J., Klaver, P., Lehnertx, K., Grunwald, T., Schaller, C., Elger, C. E., \& Fernández, G. (2001). Human memory formation is accompanied by rhinal-hippocampal coupling and decoupling Nature Neuroscience, 4(12), 1259-1264. http://dx.doi.org $/ 10.1038 / \mathrm{nn} 759$

Fernández, G., Fell, J., \& Fries, P. (2002). Response: The birth of a memory. Trends in Neurosciences, 25(6), 281-282. http://dx.doi.org/10.1016/S0166-2236(02)02177-X

Fitzgerald, P. B., Hoy, K., Gunewardene, R., Slack, C., Ibrahim, S., Bailey, M., \& Daskalakis, Z. J. (2011). A randomized tria of unilateral and bilateral prefrontal cortex transcranial magnetic stimulation in treatment-resistant major depression. Psychological Medicine, 41(6), 1187-1196. http://dx.doi.org /10.1017/S0033291710001923

Fletcher, E. M., Kussmaul, C. L., \& Mangun, G. R. (1996). Estimation of interpolation errors in scalp topographic mapping. Electroencephalography and Clinical Neurophysiology, 98(5), 422-434. http://dx.doi.org/10.1016 /0013-4694(96)95135-4

Ford, J. M., Gray, M., Faustman, W. O., Heinks, T. H., \& Mathalon, D. H. (2005). Reduced gamma-band coherence to distorted feedback during speech when what you say is not what you hear. International Journal of Psychophysiology, 57(2), $\quad 143-150 . \quad$ http://dx.doi.org/10.1016 /j.ijpsycho.2005.03.002

Friedman, D., Simpson, G. V., \& Hamberger, M. (1993). Agerelated changes in scalp topography to novel and target stimuli. Psychophysiology, 30, 383-396.

Fries, P. (2009). Neuronal gamma-band synchronization as a fundamental process in cortical computation. Annual Review of Neuroscience, 32, 209-224. http://dx.doi.org/10.1146 lannurev.neuro.051508.135603

Frith, U., \& Happé, F. (1994). Autism: Beyond theory of mind. Cognition, 50(1-3), 115-132. http://dx.doi.org/10.1016/00100277(94)90024-8

García-Larrea, L., Lukaszewicz, A. C., \& Mauguière, F. (1992). Revisiting the oddball paradigm. Non-target vs neutral stimuli and the evaluation of ERP attentional effects. Neuropsychologia, 30(8), 723-741.

Garvey, M. A., \& Gilbert, D. L. (2004). Transcranial magnetic stimulation in children. European Journal of Paediatric Neurology, 8(1), 7-19. http://dx.doi.org/10.1016 /j.ejpn.2003.11.002

George, M. S., \& Belmaker, R. H. (Eds.). (2007). Transcranial magnetic stimulation in clinical psychiatry. Arlington, VA: American Psychiatry Publishing, Inc.

George, M. S., Lisanby, S. H., Avery, D., McDonald, W. M., Durkalski, V., Pavlicova, M., ... Sackeim, H. A. (2010). Daily left prefrontal transcranial magnetic stimulation therapy for major depressive disorder: A sham-controlled randomized trial. Archives of General Psychiatry, 67(5), 507-516. http://dx.doi.org/10.1001 /archgenpsychiatry.2010.46

Gershon, A. A., Dannon, P. N., \& Grunhaus, L. (2003). Transcranial magnetic stimulation in the treatment of depression. The American Journal of Psychiatry, 160(5), 835-841. http://dx.doi.org/0.1176/appi.ajp.160.5.835

Gevins, A., Smith, M. E., McEvoy, L. K., \& Yu, D. (1997). Highresolution EEG mapping of cortical activation related to working memory: Effects of task difficulty, type of processing, and practice. Cerebral Cortex, 7(4), 374-385. http://dx.doi.org /10.1093/cercor/7.4.374

Gillberg, C., \& Billstedt, E. (2000). Autism and Asperger syndrome: coexistence with other clinical disorders. Acta Psychiatrica Scandinavica, 102(5), 321-330. http://dx.doi.org/ 10.1034/j.1600-0447.2000.102005321.x

Gomez-Gonzales, C. M., Clark, V. P., Fan, S., Luck, S. J., \& Hillyard, S. A. (1994). Sources of attention-sensitive visual event-related potentials. Brain Topography, 7(1), 41-51.

Goto, Y., Brigell, M. G., \& Parmeggiani, L. (1996). Dipolemodeling of the visual evoked P300. Journal of Psychosomatic Research, 41(1), 71-79. http://dx.doi.org /10.1016/0022-3999(96)00062-1

Gray, C. M., König, P., Engel, A. K., \& Singer, W. (1989). Oscillatory response in the cat visual cortex exhibit intercolumnar synchronization which reflects global stimulus properties. Nature, 338(6213), 334-337. http://dx.doi.org $110.1038 / 338334 \mathrm{a} 0$

Grice, S. J., Spratling, M. W., Karmiloff-Smith, A., Halit, H., Csibra, G., de Haan, M., \& Johnson, M. H. (2001). Disordered visual processing and oscillatory brain activity in autism and Williams syndrome. NeuroReport, 12(12), 2697-2700. http://dx.doi.org/10.1097/00001756-200108280-00021

Gross, E., El-Baz, A. S., Sokhadze, G. E., Sears, L., Casanova, M. F., \& Sokhadze, E. M. (2012). Induced EEG gamma oscillation alignment improves differentiation between autism and ADHD group responses in a facial categorization task. Journal of Neurotherapy, 16(2), 78-91. http://dx.doi.org /10.1080/10874208.2012.677631

Grosse-Wentrup, M., Schölkopf, B., \& Hill, J. (2011). Casual influence of gamma oscillations on the sensorimotor rhythm. Neurolmage, 56(2), 837-842. http://dx.doi.org/10.1016 /j.neuiroimage.2010.04.265

Halgren, E., Marinkovic, K., \& Chauvel, P. (1998). Generators of the late cognitive potentials in auditory and visual oddball tasks. Electroencephalography and Clinical Neurophysiology, 106(2), 156-164. http://dx.doi.org/10.1016/S00134694(97)00119-3

Happé, F., \& Frith, U. (2006). The weak coherence account: Detail-focused cognitive style in autism spectrum disorders. Journal of Autism and Developmental Disorders, 36(1), 5-25. http://dx.doi.org/10.1007/s10803-005-0039-0

Heinze, H. J., Mangun, G. R., Burchert, W., Hinrichs, H., Scholz, M., Münte, T. F., ... Hillyard, S. A. (1994). Combined spatial and temporal imaging of brain activity during visual selective attention in humans. Nature, 372(6506), 543-546. http://dx.doi.org/10.1038/372543a0

Henderson, H., Schwartz, C., Mundy, P., Burnette, C., Sutton, S., Zahka, N., \& Pradella, A. (2006). Response monitoring, the error-related negativity, and differences in social behavior in autism. Brain and Cognition, 61(1), 96-109. http://dx.doi.org /10.1016/j.bandc.2005.12.009

Hensley, M. K., El-Baz, A. S., Sokhadze, E. M., Sears, L., \& Casanova, M. F. (2014). Effects of 18 session TMS therapy of gamma coherence in autism. Psychophysiology, 51, S16.

Herrmann, C. S., \& Demiralp, T. (2005). Human EEG gamma oscillations in neuropsychiatric disorders. Clinical Neurophysiology, 116(12), 2719-2733. http://dx.doi.org /10.1016/j.clinph.2005.07.007

Herrmann, C. S., \& Knight, R. T. (2001). Mechanisms of human attention: Event-related potentials and oscillations. Neuroscience and Biobehavioral Reviews, 25(6), 465-476. http://dx.doi.org/10.1016/S0149-7634(01)00027-6

Herrmann, C. S., \& Mecklinger, A. (2000). Magnetoencephalographic responses to illusory figures: Early 
evoked gamma is affected by processing of stimulus features. International Journal of Psychophysiology, 38(3), 265-281. http://dx.doi.org/10.1016/S0167-8760(00)00170-7

Herrmann, C. S., \& Mecklinger, A. (2001). Gamma activity in human EEG is related to high-speed memory comparisons during object selective attention. Visual Cognition, 8(3-5), 593-608. http://dx.doi.org/10.1080/13506280143000142

Herrmann, C. S., Munk, M. H. J., \& Engel, A. K. (2004). Cognitive functions of gamma-band activity: Memory match and utilization. Trends in Cognitive Sciences, 8(8), 347-355. http://dx.doi.org/10.1016/j.tics.2004.06.006

Hillyard, S. A., \& Anllo-Vento, L. (1998). Event-related brain potentials in the study of visual selective attention. Proceedings of the National Academy of Sciences of the USA, 95(3), 781-787.

Hoffman, R. E., \& Cavus, I. (2002). Slow transcranial magnetic stimulation, long-term depotentiation, and brain hyperexcitability disorders. The American Journal of Psychiatry, 159(7), 1093-1102. http://dx.doi.org/10.1176 /appi.ajp.159.7.1093

Horrell, T., El-Baz, A., Baruth, J., Tasman, A., Sokhadze, G., Stewart, C., \& Sokhadze, E. (2010). Neurofeedback effects on evoked and induced EEG gamma band reactivity to drug related cues in cocaine addiction. Journal of Neurotherapy, 14(3), 195-216. http://dx.doi.org/10.1080 /10874208.2010.501498

Industrial Acoustics Co. camera [Apparatus]. Bronx, NY: IAC Acoustics.

Isler, J. R., Martien, K. M., Grieve, P. G., Stark, R. I., \& Herbert, M. R. (2010). Reduced functional connectivity in visual evoked potentials in children with autism spectrum disorder. Clinical Neurophysiology, 121(12), 2035-2043. http://dx.doi.org/10.1016/j.clinph.2010.05.004

Joliot, M., Ribary, M., \& Llinás, R. (1994). Human oscillatory brain activity near $40 \mathrm{~Hz}$ coexists with temporal cognitive binding. Proceedings of the National Academy of Sciences of the USA, 91(24), 11748-11751.

Just, M. A., Cherkassky, V. L., Keller, T. A., \& Minshew, N. J. (2004). Cortical activation and synchronization during sentence comprehension in high-functioning autism: Evidence of underconnectivity. Brain, 127(8), 18111821. http://dx.doi.org /10.1093/brain/awh199

Kahana, M. J. (2006). The cognitive correlates of human brain oscillations. The Journal of Neuroscience, 26(6), 1669-1672. http://dx.doi.org/10.1523/JNEUROSCI.3737-05c.2006

Kaiser, J., \& Lutzenberger, W. (2003). Induced gamma-band activity and human brain function. The Neuroscientist, 9(6), 475-484. http://dx.doi.org/10.1177/1073858403259137

Kanizsa, G. (1976). Subjective contours. Scientific American, 235, $48-52$.

Karakaş, S., \& Başar, E. (1998). Early gamma response is sensory in origin: A conclusion based on cross-comparison of results from multiple experimental paradigms. International Journal of Psychophysiology, 31(1), 13-31. http://dx.doi.org /10.1016/S0167-8760(98)00030-0

Karakaş, S., Başar-Eroğlu, C., Özesmi, C., Kafadar, H., \& Erzengin, Ö. Ü. (2001). Gamma response of the brain: a multifunctional oscillation that represents bottom-up with topdown processing. International Journal of Psychophysiology, 39, 137-150. http://dx.doi.org/10.1016/S01678760(00)00137-9

Karakaş, S., Erzengin, Ö. U., \& Başar, E. (2000). The genesis of human event-related responses explained through the theory of oscillatory neural assemblies. Neuroscience Letters, 285(1), 45-48. http://dx.doi.org/10.1016/S03043940(00)01022-3

Karakaş, S., Tüfekçic, I., Bekçi, B., Çakmak, E., Doğutepe, E., Erzengin, Ö. U., ... Arkan, O. (2006). Early time-locked gamma response and gender specificity. International Journal of Psychophysiology, 60(3), 225-239. http://dx.doi.org /10.1016/j.jpsycho.2005.05.009

Katayama, J., \& Polich, J. (1998). Stimulus context determines P3a and P3b. Psychophysiology, 35(1), 23-33. http://dx.doi.org/10.1111/1469-8986.3510023

Keil, A., Müller, M. M., Ray, W. J., Gruber, T., \& Elbert, T. (1999). Human gamma band activity and perception of a Gestalt. The Journal of Neuroscience, 19(16), 7152-7161.

Kéita, L., Mottron, L., Dawson, M., \& Bertone, A. (2011). Atypical lateral connectivity: A neural basis for altered visuospatial processing in autism. Biological Psychiatry, 70(9), 806-811. http://dx.doi.org/10.1016/j.biopsych.2011.07.031

Kemner, C., van der Gaag, R. J., Verbaten, M., \& van Engeland, H. (1999). ERP differences among subtypes of pervasive developmental disorders. Biological Psychiatry, 46(6), 781789.

Kemner, C., Verbaten, M. N., Cuperus, J. M., Camfferman, G., \& van Engeland, H. (1994). Visual and somatosensory eventrelated brain potentials in autistic children and three different control groups. Electroencephalography and Clinical Neurophysiology, 92(3), 225-237.

Kemner, C., Verbaten, M. N., Cuperus, J. M., Camfferman, G., \& van Engeland, H. (1995). Auditory event-related potentials in autistic children and three different control groups. Biological Psychiatry, 38, 150-165. http://dx.doi.org/10.1016/00063223(94)00247-Z

Kenemans, J. L., Kok, A., \& Smulders, F. T. (1993). Event-related potentials to conjunctions of spatial frequency and orientation as a function of stimulus parameters and response requirements. Electroencephalography and Clinical Neurophysiology, 88(1), 51-63. http://dx.doi.org/10.1016 10168-5597(93)90028-N

Khedr, E. M., Rothwell, J. C., Ahmed, M. A., \& El-Atar, A. (2008). Effect of daily repetitive transcranial magnetic stimulation for treatment of tinnitus: Comparison of different stimulus frequencies. Journal of Neurology, Neurosurgery, and Psychiatry, $\quad$ 79(2), $\quad$ 212-215. http://dx.doi.org/10.1136 /jnnp.2007.127712

Knight, R. T. (1984). Decreased response to novel stimuli after prefrontal lesions in man. Electroencephalography and Clinical Neurophysiology, 59(1), 9-20. http://dx.doi.org /10.1016/0168-5597(84)90016-9

Knight, R. T. (1997). Distributed cortical network for visual attention. Journal of Cognitive Neuroscience, 9, 75-91. http://dx.doi.org/10.1162/jocn.1997.9.1.75

Lavdas, A. A., Grigoriou, M., Pachnis, V., \& Parnavelas, J. G. (1999). The medial ganglionic eminence gives rise to a population of early neurons in the developing cerebral cortex. Journal of Neuroscience, 19(18), 7881-7888.

Le Couteur, A., Lord, C., \& Rutter, M. (2003). The autism diagnostic interview-revised (ADI-R). Los Angeles, CA: Western Psychological Services.

Lenz, D., Schadow, J., Thaerig, S., Busch, N. A., \& Herrmann, C. S. (2007). What's that sound? Matches with auditory longterm memory induce gamma activity in human EEG. International Journal of Psychophysiology, 64(1), 31-38. http://dx.doi.org/10.1016/j.ijpsycho.2006.07.008

Lin, K. L., \& Pascual-Leone, A. (2002). Transcranial magnetic stimulation and its applications in children. Chang Gung Medical Journal, 25(7), 424-436.

Llinás, R., \& Ribary, U. (1993). Coherent $40-\mathrm{Hz}$ oscillation characterizes dream state in humans. Proceedings of the National Academy of Sciences of the USA, 90(5), 2078-2081. http://dx.doi.org/10.1073/pnas.90.5.2078

Loo, C. K., \& Mitchell, P. B. (2005). A review of the efficacy of transcranial magnetic stimulation (TMS) treatment for depression, and current and future strategies to optimize efficacy. Journal of Affective Disorders, 88(3), 255-267. http://dx.doi.org/10.1016/j.jad.2005.08.001 
Luck, S. J., Heinze, H. J., Mangun, G. R., \& Hillyard, S. A. (1990). Visual event-related potentials index focused attention within bilateral stimulus arrays. ii. Functional dissociation of P1 and N1 components. Electroencephalography and Clinical Neurophysiology,75(6), 528-542. http://dx.doi.org/10.1016 /0013-4694(90)90139-B

Luu, P., Tucker, D. M., Englander, R., Lockfeld, A., Lutsep, H., \& Oken, B. (2001). Localizing acute stroke-related EEG changes: Assessing the effects of spatial undersampling. Journal of Clinical Neurophysiology, 18(4), 302-317.

Makeig, S., Westerfield, M., Jung, T.-P., Enghoff, S., Townsend, J., Courchesne, E., \& Sejnowski, T. J. (2002). Dynamic brain sources of visual evoked responses. Science, 295(5555), 690-694. http://dx.doi.org/10.1126/science.1066168

Mann, E. O., \& Paulsen, O. (2007). Role of GABAergic inhibition in hippocampal network oscillations. Trends in Neurosciences, 30(7), 343-349. http://dx.doi.org/10.1016 /j.tins.2007.05.003

Mecklinger, A., Maess, B., Opitz, B., Pfeifer, E., Cheyne, D., \& Weinberg, H. (1998). A MEG analysis of the P300 in visual discrimination tasks. Electroencephalography and Clinical Neurophysiology, 108(1), 45-66.

Milne, E., Scope, A., Pascalis, O., Buckley, D., \& Makeig, S. (2009). Independent component analysis reveals atypical electroencephalographic activity during visual perception in individuals with autism. Biological Psychiatry, 65(1), 22-30. http://dx.doi.org/10.1016/j.biopsych.2008.07.017

Minshew, N. J., Goldstein, G., \& Siegel, D. J. (1997) Neuropsychologic functioning in autism: Profile of a complex information processing disorder. Journal of International Neuropsychology Society, 3(4), 303-316.

Minshew, N. J. \& Williams, D. L. (2007). The New Neurobiology of Autism: Cortex, Connectivity, and Neuronal Organization. Archives of Neurology, 64(7), 945-950. http://dx.doi.org /10.1001/archneur.64.7.945

Müller, M. M., Bosch, J., Elbert, T., Kreiter, A., Sosa, M. V., Sosa, P. V., \& Rockstroh, B. (1996). Visually induced gamma-band responses in human electroencephalographic activity - a link to animal studies. Experimental Brain Research, 112(1), 96102. http://dx.doi.org/10.1007/BF00227182

Müller, M. M., \& Gruber, T. (2001). Induced gamma-band responses in the human EEG are related to attentional information processing. Visual Cognition, 8, 579-592.

Müller, M. M., Gruber, T., \& Keil, A. (2000). Modulation of induced gamma band activity in the human EEG by attention and visual information processing. International Journal of Psychophysiology, 38(3), 283-299. http://dx.doi.org/10.1016 IS0167-8760(00)00171-9

Murias, M., Webb, S. J., Greenson, J., \& Dawson, G. (2007). Resting state cortical connectivity reflected in EEG coherence in individuals with autism. Biological Psychiatry, 62(3), 270273. http://dx.doi.org/10.1016/j.biopsych.2006.11.012

Murphy, K. R., \& Myors, B. (2004). Statistical power analysis: A simple and general model for traditional and modern hypothesis tests (2nd ed.). Mahwah, NJ: Lawrence Erlbaum Associates.

Näätänen, R. A., Gaillard, A. W. K., \& Mäntysalo, S. (1978). Early selective-attention effect on evoked potential reinterpreted. Acta Psychologica, 42(4), 313-329.

Näätänen, R., \& Michie, P. T. (1979). Early selective-attention effects on the evoked potential: A critical review and reinterpretation. Biological Psychology, 8(2), 81-136. http://dx.doi.org/10.1016/0301-0511(79)90053-X

Näätänen, R., Schröger, E., Karakaş, S., Tervaniemi, M., \& Paavilainen, P. (1993). Development of a memory trace for a complex sound in the human brain. NeuroReport, 4, 503-506.

Oades, R. D., Walker, M. K., Geffen, L. B., \& Stern, L. M. (1988). Event-related potentials in autistic and healthy children on an auditory choice reaction time task. International Journal of Psychophysiology, 6(1), 25-37.
Oberman, L. M., Rotenberg, A., \& Pascual-Leone, A. (2013). Use of transcranial magnetic stimulation in autism spectrum disorders. Journal of Autism and Developmental Disorders, 45(2), 524-536. http://dx.doi.org/10.1007/s10803-013-1960-2

Ogawa, A., Ukai, S., Shinosaki, K., Yamamoto, M., Kawaguchi, S., Ishii, R., \& Takeda, M. (2004). Slow repetitive transcranial magnetic stimulation increases somatosensory highfrequency oscillations in humans. Neuroscience Letters, 358(3), 193-196. http://dx.doi.org/10.1016 /j.neulet.2004.01.038

Orekhova, E. V., \& Stroganova, T. A. (2014). Arousal and attention re-orienting in autism spectrum disorders: Evidence from auditory event-related potentials. Frontiers in Human Neuroscience, $\quad 8(1), \quad 34 . \quad$ http://dx.doi.org/10.3389 /fnhum.2014.00034

Orekhova, E. V., Stroganova, T. A., Nygren, G., Tsetlin, M. M., Posikera, I. N., Gillberg, C., \& Elam, M. (2007). Excess of high frequency electroencephalogram oscillations in boys with autism. Biological Psychiatry, 62(9), 1022-1029. http://dx.doi.org/10.1016/j.biopsych.2006.12.029

Padmanabhapillai, A., Porjesz, B., Ranganathan, M., Jones, K. A., Chorlian, D. B., Tang, Y., ... Begleiter, H. (2006). Suppression of early evoked gamma band response in male alcoholics during a visual oddball task. International Journal of Psychophysiology, 60(1), 15-26. http://dx.doi.org/10.1016 /j.ijpsycho.2005.03.026

Pascual-Leone, A., Walsh, V., \& Rothwell, J. (2000). Transcranial magnetic stimulation in cognitive neuroscience-virtual lesion, chronometry, and functional connectivity. Current Opinion in Neurobiology, 10(2), 232-237. http://dx.doi.org/10.1016 /S0959-4388(00)00081-7

Pfurtscheller, G., \& Aranibar, A. (1977). Event-related cortical desynchronisation detected by power measurements of scalp EEG. Electroencephalography and Clinical Neurophysiology, 42(6), 817-826. http://dx.doi.org/10.1016/00134694(77)90235-8

Pfurtscheller, G., \& Lopes da Silva, F. H. (1999). Event-related EEG/MEG synchronization and desynchronization: Basic principles. Clinical Neurophysiology, 110(11), 1842-1857. http://dx.doi.org/10.1016/S1388-2457(99)00141-8

Polich, J. (2003). Theoretical overview of P3a and P3b. In J. Polich (Ed.), Detection of change: Event-related potential and fMRI findings (pp. 83-98). Boston: Kluwer Academic Press. http://dx.doi.org/10.1007/978-1-4615-0294-4_5

Port, R. G., Anwar, A. R., Ku, M., Carlson, G. C., Siegel, S. J., \& Roberts, T. P. (2015). Prospective MEG biomarkers in ASD: Pre-clinical evidence and clinical promise of electrophysiological signatures. Yale Journal of Biology and Medicine, 88(1), 25-36.

Potts, G. F., Dien, J., Hartry-Speiser, A. L., McDougal, L. M., \& Tucker, D. M. (1998). Dense sensor array topography of the event-related potential to task-relevant auditory stimuli. Electroencephalography and Clinical Neurophysiology, 106(5), 444-456. http://dx.doi.org/10.1016/S00134694(97)00160-0

Potts, G. F., Liotti, M., Tucker, D. M., \& Posner, M. I. (1996). Frontal and inferior temporal cortical activity in visual target detection: Evidence from high spatially sampled event-related potentials. Brain Topography, 9(1), 3-14. http://dx.doi.org /10.1007/BF01191637

Potts, G. F., Patel, S. H., \& Azzam, P. N. (2004). Impact of instructed relevance on the visual ERP. International Journal Psychophysiology, 52(2), 197-209. http://dx.doi.org/10.1016 /j.ijpsycho.2003.10.005

Pritchard, W. (1981). Psychophysiology of P300. Psychological Bulletin, 89(3), 506-540. http://dx.doi.org/10.1037/00332909.89.3.506

Puts, N. A. J., Wodka, E. L., Tommerdahl, M., Mostofsky, S. H., \& Edden, R. A. E. (2014). Impaired tactile processing in children 
with autism spectrum disorder. Journal of Neurophysiology, 111(9), 1803-1811. http://dx.doi.org/10.1152/jn.00890.2013

Quintana, H. (2005). Transcranial magnetic stimulation in persons younger than the age of 18. Journal of ECT, 21(2), 88-95.

Rippon, G., Brock, J., Brown, C., \& Boucher, J. (2007). Disordered connectivity in the autistic brain: Challenges for the 'new psychophysiology.' International Journal of Psychophysiology, 63(2), 164-172. http://dx.doi.org/10.1016 /j.ijpsycho.2006.03.012

Rogers, R. L., Basile, L. F. H., Papanicolaou, A. C., \& Eisenberg, H. M. (1993). Magnetoencephalography reveals two distinct sources associated with late positive evoked potentials during visual oddball task. Cerebral Cortex, 3(2), 163-169. $\mathrm{http}: / / \mathrm{dx}$.doi.org/10.1093/cercor/3.2.163

Rojas, D. C., \& Wilson, L. B. (2014). Gamma-band abnormalities as markers of autism spectrum disorders. Biomarkers in Medicine, 8(3), 353-368. http://dx.doi.org/10.2217 /bmm.14.15

Rossi, S., \& Rossini, P. M. (2004). TMS in cognitive plasticity and the potential for rehabilitation. Trends in Cognitive Sciences, 8(6), 273-279. http://dx.doi.org/10.1016/j.tics.2004.04.012

Rubenstein, J. L. R., \& Merzenich, M. M. (2003). Model of autism: Increased ratio of excitation/inhibition in key neural systems. Genes, Brain and Behavior, 2(5), 255-267. http://dx.doi.org/10.1034/j.1601-183X.2003.00037.x

Seri, S., Cerquiglini, A., Pisani, F., \& Curatolo, P. (1999). Autism in tuberous sclerosis: Evoked potential evidence for a deficit in auditory sensory processing. Clinical Neurophysiology, 110, 1825-1830.

Serial Response Box [Apparatus]. Sharpsburg, PA: Psychology Software Tools, Inc.

Sheer, D. E. (1976). Focused arousal and $40 \mathrm{~Hz}$ EEG. In R. M. Knight, \& D. J. Baker (Eds.), The neuropsychology of learning disorders. Baltimore, MD: University Park Press.

Shibata, T., Shimoyama, I., Ito, T., Abla, D., Iwasa, H., Koseki, K., ... Nakajima, Y. (1999). Attention changes the peak latency of the visual gamma-band oscillation of the EEG. NeuroReport, 10(6), 1167-1170.

Shuang, M., Liu, J., Jia, M. X., Yang, J. Z., Wu, S. P., Gong, X. H., ... Zhang, D. (2004). Family-based association study between autism and glutamate receptor 6 gene in Chinese Han trios. American Journal of Medical Genetics: Neuropsychiatric Genetics, 131B(1), 48-50. http://dx.doi.org /10.1002/ajmg.b.30025

Singer, W. (1999). Neuronal synchrony: A versatile code for the definition of relations? Neuron, 24(1), 49-65, 111-125.

Sokhadze, E., Baruth, J., El-Baz, A., Horrell, T., Sokhadze, G., Carroll, T., ... Casanova, M. F. (2010). Impaired error monitoring and correction function in autism. Journal of Neurotherapy, 14(2), 79-95. http://dx.doi.org/10.1080 /10874201003771561

Sokhadze, E. M., Baruth, J. M., Sears, L., Sokhadze, G. E., ElBaz, A. S., \& Casanova, M. F. (2012). Prefrontal neuromodulation using rTMS improves error monitoring and correction function in autism. Applied Psychophysiology and Biofeedback, 37(2), 91-102. http://dx.doi.org/10.1007 /s10484-012-9182-5

Sokhadze, E., Baruth, J., Tasman, A., Mansoor, M., Ramaswamy, R., Sears, L., ... Casanova, M. F. (2010). Low-frequency repetitive transcranial magnetic stimulation (rTMS) affects event-related potential measures of novelty processing in autism. Applied Psychophysiology and Biofeedback, 35(2), 147-161. http://dx.doi.org/10.1007/s10484-009-9121-2

Sokhadze, E., Baruth, J., Tasman, A., Sears, L., Mathai, G., ElBaz, A., \& Casanova, M. F. (2009). Event-related potential study of novelty processing abnormalities in autism. Applied Psychophysiology and Biofeedback, 34(1), 37-51. http://dx.doi.org/10.1007/s10484-009-9074-5

Sokhadze, E. M., Casanova, M. F., \& Baruth, J. (2013). Transcranial magnetic stimulation in autism spectrum disorders. In L. Alba-Ferrara (Ed.), Transcranial magnetic stimulation: methods, clinical uses and effect on the brain (pp. 219-231). New York: NOVA Science Publishers.

Sokhadze, E. M., El-Baz, A., Baruth, J., Mathai, G., Sears, L., \& Casanova, M. F. (2009). Effect of a low frequency repetitive transcranial magnetic stimulation (rTMS) on gamma frequency oscillations and event-related potentials during processing of illusory figures in autism. Journal of Autism and Developmental Disorders, 39(4), 619-634. http://dx.doi.org /10.1007/s10803-008-0662-7

Sokhadze, E. M., El-Baz, A. S., Sears, L. L., Opris, I., \& Casanova, M. F. (2014). rTMS neuromodulation improves electrocortical functional measures of information processing and behavioral responses in autism. Frontiers in Systems Neuroscience, $\quad 8, \quad$ 134. http://dx.doi.org/10.3389 /fnsys.2014.00134

Sokhadze, E. M., El-Baz, A. S., Tasman, A., Sears, L. L., Wang, Y., Lamina, E. V., \& Casanova, M. F. (2014). Neuromodulation integrating rTMS and neurofeedback for the treatment of autism spectrum disorder: Aan exploratory study. Applied Psychophysiology and Biofeedback, 39(3-4), 237257. http://dx.doi.org/10.1007/s10484-014-9264-7

Srinivasan, R., Tucker, D. M., \& Murias, M. (1998). Estimating the spatial Nyquist of the human EEG. Behavioral Research Methods, Instruments, and Computers, 30(1), 8-19. http://dx.doi.org/10.3758/BF03209412

Stroganova, T. A., Butorina, A. V., Sysoeva, O. V., Prokofyev, A. O., Nikolaeva, A. Y., Tsetlin, M. M., \& Orekhova, E. V. (2015). Altered modulation of gamma oscillation frequency by speed of visual motion in children with autism spectrum disorders. Journal of Neurodevelopmental Disorders, 7(1), 21. http://dx.doi.org/10.1186/s11689-015-9121-x

Stroganova, T. A., Nygren, G., Tsetlin, M. M., Posikera, I. N., Gillberg, C., Elam, M., \& Orekhova, E. V. (2007). Abnormal EEG lateralization in boys with autism. Clinical Neurophysiology, 118(8), 1842-1854. http://dx.doi.org /10.1016/j.clinph.2007.05.005

Stroganova, T. A., Orekhova, E. V., Prokofyev, A. O., Tsetlin, M. M., Gratchev, V. V., Morozov, A. A., \& Obukhov, Y. V. (2012). High-frequency oscillatory response to illusory contour in typically developing boys and boys with autism spectrum disorders. Cortex, 48(6), 701-717. http://dx.doi.org/10.1016 /j.cortex.2011.02.016

Sun, L., Grützner, C., Bölte, S., Wibral, M., Tozman, T., Schlitt, S., ... Uhlhaas, P. J. (2012). Impaired gamma-band activity during perceptual organization in adults with autism spectrum disorders: Evidence for dysfunctional network activity in frontal-posterior cortices. The Journal of Neuroscience, 32(28), 9563-9573. $\quad \mathrm{http}: / / \mathrm{dx}$.doi.org/10.1523 IJNEUROSCI.1073-12.2012

Tallon-Baudry, C. (2003). Oscillatory synchrony and human visual cognition. Journal of Physiology-Paris, 97(2-3), 355-363. http://dx.doi.org/10.1016/j.jphysparis.2003.09.009

Tallon-Baudry, C., Bertrand, O., Delpuech, C., \& Pernier, J. (1996). Stimulus specificity of phase-locked and non-phaselocked $40 \mathrm{~Hz}$ visual responses in human. The Journal of Neuroscience, 16(13), 4240-4249.

Tallon-Baudry, C., Bertrand, O., Hénaff, M.-A., Isnard, J., \& Fischer, C. (2005). Attention modulates gamma-band oscillations differently in the human lateral occipital cortex and fusiform gyrus. Cerebral Cortex, 15(5), 654-662. http://dx.doi.org/10.1093/cercor/bhh167

Tallon-Baudry, C., Bertrand, O., Peronnet, F., \& Pernier, J. (1998). Induced gamma-band activity during the delay of a visual short-term memory task in humans. The Journal of Neuroscience, 18(11), 4244-4254.

Tavassoli, T., Bellesheim, K., Tommerdahl, M., Holden, J. M., Kolevzon, A., \& Buxbaum, J. D. (2016). Altered tactile processing in children with autism spectrum disorder. Autism Research, 9(6), 616-620. http://dx.doi.org/10.1002/aur.1563 
Thakkar, K. N., Polli, F. E., Joseph, R. M., Tuch, D. S., Hadjikhani, N., Barton, J. J. S., \& Manoach, D. S. (2008). Response monitoring, repetitive behaviour and anterior cingulate abnormalities in autism spectrum disorders (ASD). Brain, 131(9), 2464-2478. http://dx.doi.org/10.1093/brain lawn099

Townsend, J., Westerfield, M., Leaver, E., Makeig, S., Jung, T.P., Pierce, K., \& Courchesne, E. (2001). Event-related brain response abnormalities in autism: Evidence for impaired cerebello-frontal spatial attention networks. Cognitive Brain Research, 11(1), 127-145. http://dx.doi.org/10.1016/S09266410(00)00072-0

Uhlhaas, P. J., \& Singer, W. (2007). What do disturbances in neural synchrony tell us about autism? Biological Psychiatry, 62(3), 190-191. http://dx.doi.org/10.1016 /j.biopsych.2007.05.023

USE3 Physiolab [Computer software]. (2004). Poulsbo, WA: J\&J Engineering, Inc.

Uzunova, G., Pallanti, S., \& Hollander, E. (2015). Excitatory/inhibitory imbalance in autism spectrum disorders: Implications for interventions and therapeutics. The World Journal of Biological Psychiatry, 17(3), 174-186. http://dx.doi.org /10.3109/15622975.2015.1085597

Vlamings, P. H. J. M., Jonkman, L. M., Hoeksma, M. R., van Engeland, H., \& Kemner, C. (2008). Reduced error monitoring in children with autism spectrum disorder: An ERP study. European Journal of Neuroscience, 28(2), 399-406. http://dx.doi.org/10.1111/j.1460-9568.2008.06336.x

Von Stein, A., Rappelsberger, P., Sarnthein, J., \& Petsche, H. (1999). Synchronization between temporal and parietal cortex during multimodal object processing in man. Cerebral Cortex, 9(2), 137-150. http://dx.doi.org/10.1093/cercor/9.2.137

Wagner, T., Rushmore, J., Eden, U., \& Valero-Cabre, A. (2009). Biophysical foundations underlying TMS: Setting the stage for an effective use of neurostimulation in the cognitive neurosciences. Cortex, 45(9), 1025-1034. http://dx.doi.org/10.1016/j.cortex.2008.10.002

Wall, C. A., Croarkin, P. E., Sim, L. A., Husain, M. M., Janicak, P. G., Kozel, F. A., ... Sampson, S. M. (2011). Adjunctive use of repetitive transcranial magnetic stimulation in depressed adolescents: A prospective, open pilot study. The Journal of Clinical Psychiatry, 72(9), 1263-1269. http://dx.doi.org /10.4088/JCP. $11 \mathrm{~m} 07003$

Wassermann, E. M., Grafman, J., Berry, C., Hollnagel, C., Wild, K., Clark, K., \& Hallett, M. (1996). Use and safety of a new repetitive transcranial magnetic stimulator. Electroencephalography and Clinical Neurophysiology, 101(5), 412-417. http://dx.doi.org/10.1016/S0921884X(96)96004-X

Wassermann, E. M., \& Lisanby, S. H. (2001). Therapeutic application of repetitive transcranial magnetic stimulation: A review. Clinical Neurophysiology, 112(8), 1367-1377. http://dx.doi.org/10.1016/S1388-2457(01)00585-5

Wassermann, E. M., \& Zimmermann, T. (2012). Transcranial magnetic stimulation: Therapeutic promises and scientific gaps. Pharmacology and Therapeutics, 133(1), 98-107. http://dx.doi.org/10.1016/j.pharmthera.2011.09.003

Wechsler, D. (1999). Wechsler abbreviated scale of intelligence. San Antonio, TX: Harcourt Assessment, Inc.

Wechsler, D. (2003). Wechsler intelligence scale for children (4th ed.). San Antonio, TX: Harcourt Assessment, Inc.

Welchew, D. E., Ashwin, C., Berkouk, K., Salvador, R., Suckling, J., Baron-Cohen, S., \& Bullmore, E. (2005). Functional disconnectivity of the medial temporal lobe in Asperger's syndrome. Biological Psychiatry, 57(9), 991-998. http://dx.doi.org/10.1016/j.biopsych.2005.01.028

Werkle-Bergner, M., Shing, Y. L., Müller, V., Li, S.-C., \& Lindenberger, U. (2009). EEG gamma-band synchronization in visual coding from childhood to old age: Evidence from evoked power and inter-trial phase locking. Clinical Neurophysiology, 120(7), 1291-1302. http://dx.doi.org/ 10.1016/j.clinph.2009.04.012

Whittington, M. A., Traub, R. D., Kopell, N., Ermentrout, B., \& Buhl, E. H. (2000). Inhibition-based rhythms: Experimental and mathematical observations on network dynamics. International Journal of Psychophysiology, 38(3), 315-336. http://dx.doi.org/10.1016/S0167-8760(00)00173-2

Wilson, T. W., Rojas, D. C., Reite, M. L., Teale, P. D., \& Rogers, S. J. (2007). Children and adolescents with autism exhibit reduced MEG steady-state gamma responses. Biological Psychiatry, 62(3), 192-197. http://dx.doi.org/10.1016 /j.biopsych.2006.07.002

Wu, A. D., Fregni, F., Simon, D. K., Deblieck, C., \& PascualLeone, A. (2008). Noninvasive brain stimulation for Parkinson's disease and dystonia. Neurotherapeutics, 5(2), 345-361. http://dx.doi.org/10.1016/j.nurt.2008.02.002

Yamazaki, T., Kamijo, K., Kenmochi, A., Fukuzumi, S., Kiyuna, T., Takaki, Y., \& Kuroiwa, Y. (2000). Multiple equivalent current dipole source localization of visual event-related potentials during oddball paradigm with motor response. Brain Topography, 12(3), 159-175. http://dx.doi.org/10.1023 IA: 1023467806268

Ziemann, U. (2004). TMS induced plasticity in human cortex. Reviews in the Neurosciences, 15(4), 253-266. http://dx.doi.org/10.1515/REVNEURO.2004.15.4.253

Received: July 23, 2016

Accepted: August 16, 2016

Published: September 2, 2016 